A N N A L E S Annales de Bretagne et des Pays de l'Ouest

\title{
Guerre de course et commerce maritime en Normandie au temps de Mazarin
}

Piracy, privateering and commerce in Normandy in Mazarin's time

\section{Édouard Delobette}

\section{(2) OpenEdition}

1 Journals

\section{Édition électronique}

URL : http://journals.openedition.org/abpo/3720

DOI : $10.4000 /$ abpo.3720

ISBN : 978-2-7535-7411-3

ISSN : $2108-6443$

\section{Éditeur}

Presses universitaires de Rennes

Édition imprimée

Date de publication : 20 décembre 2017

Pagination : 25-64

ISBN : 978-2-7535-7409-0

ISSN : 0399-0826

\section{Référence électronique}

Édouard Delobette, «Guerre de course et commerce maritime en Normandie au temps de Mazarin », Annales de Bretagne et des Pays de l'Ouest [En ligne], 124-4 | 2017, mis en ligne le 20 décembre 2019, consulté le 03 janvier 2020. URL : http://journals.openedition.org/abpo/3720 ; DOI : 10.4000/abpo. 3720

Ce document a été généré automatiquement le 3 janvier 2020

(c) Presses universitaires de Rennes 


\title{
Guerre de course et commerce maritime en Normandie au temps de Mazarin
}

\author{
Piracy, privateering and commerce in Normandy in Mazarin's time
}

Édouard Delobette

Thus wildly we live,

Thus freely we give What Heaven as freely bestows.

We were not made

For labour and trade,

Which fools on each other impose ${ }^{1}$. Henry Purcell, The Fairy Queen, acte V.

1 Au cours du printemps 1644, lors de son retour de "Ouestrefort " (Wexford, Irlande)2, la barque la Blanche et son équipage havrais sont capturés dans le travers de Plymouth par le corsaire anglais Jean Raoul (John Rawle), maitre de pinasse (voir figure 1, cidessous) $)^{3}$. Ce dernier, «plus cruel que n'auroit été un Corsaire d'Alger », s'entête à faire avouer la propriété irlandaise du bâtiment, pour le saisir, en torturant en vain le «page » du bord (le mousse), qui a la corde au cou, des mèches à feu allumées dans les mains. Le pilote huguenot André Lesbahy se voit alors proposer un intéressement aux gains des prises en échange de son faux témoignage. Devant son refus, Rawle le fait rosser à coups de bâton puis confisque le navire et la cargaison. L'équipage havrais, débarqué sans ménagement à Plymouth, demeure abandonné à lui-même pendant deux mois avant de rentrer en France «pieds nus \& leurs chemises pourries au dos ». Les armateurs estiment la perte totale du voyage à plus de trente mille livres tournois ${ }^{4}$.

2 Cette dramatique affaire s'intègre dans une période de conflits maritimes qui « ensauvagent » à nouveau la Manche et la mer du Nord, du fait du mercantilisme : " Mercantilist logic was the logic of violence in an age of violence ${ }^{5}$ "; le diplomate Thomas Roe soutient même que les conflits habilement entretenus entre les autres puissances maritimes sont indissociables de l'expansion commerciale de l'Angleterre ${ }^{6}$. C'est 
pourquoi l'affaire de la Blanche confirme aussi l'irruption violente en Manche de l'économie de prédation, manifestée par la piraterie, la course ou l'embargo, et subie par les ports et trafics de Normandie durant les tensions, crises et guerres de la " décennie cruciale (1648-1660) ${ }^{7}$ ». Comment, dans un environnement maritime aussi hostile, les marchands armateurs normands poursuivent-ils leurs affaires et réorientent-ils leurs stratégies durant les années 1650 sans bénéficier de l'appui du pouvoir royal?

3 La réponse, fort complexe, évoque tour à tour les difficultés d'ordre naval, politique ou administratif venant de la part de l'État, des gouverneurs ou des amirautés auxquelles se heurtent les marchands, aborde les modes de résilience commerciale des marchands armateurs dans un contexte de quasi-guerre commerciale avec l'Angleterre, en s'appuyant sur les statistiques portuaires havraises, puis détaille en dernière partie la stratégie de pluriactivité commerciale mise en œuvre par l'armateur rouennais Jacques Regnault en croisant les récents apports historiographiques anglais ou écossais, des archives inédites de la Table de marbre du Palais à Rouen ou des sièges d'amirauté de Normandie ainsi que les contrats du tabellionage rouennais ${ }^{8}$.

Figure 1. Plan d'une pinasse du début du XVII siècle

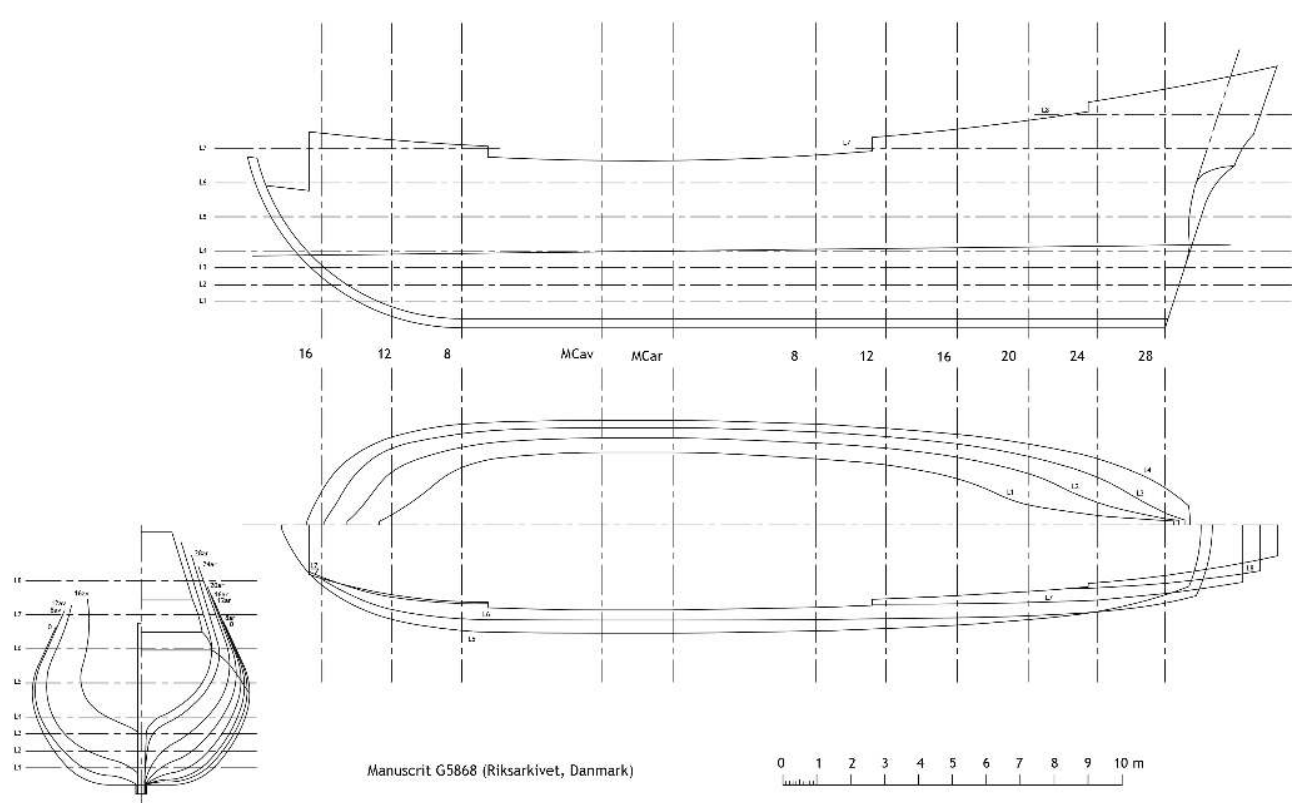

Source : DAEFFLER, Michel, Formes de carène et navires de combat : l'invention du vaisseau de ligne en Angleterre (1560-1642), Caen, Centre de recherche d'histoire quantitative, 2004 : plans d'une pinasse du début du xvı" siècle, d'après le manuscrit G 5868 déposé au Riksarkivet de Copenhague. Avec l'aimable autorisation de l'auteur.

\section{Quand les rouages de l'État nuisent au commerce de mer}

\section{La pression navale de l'État}

$\mathrm{Au}$ lieu de bénéficier du soutien du pouvoir royal durant cette turbulente période, les entreprises commerciales et maritimes des marchands armateurs normands se heurtent au contraire à la pression navale de l'État, aux abus de pouvoir commis par les 
gouverneurs de la province et à la prévarication générale régnant dans les sièges d'amirauté. Les levées d'officiers, de matelots et d'ouvriers spécialisés pour le service de la Marine royale désorganisent les armements marchands et l'économie portuaire. L'Inscription maritime n'existant pas encore, les équipages de la flotte du Levant basée à Toulon sont souvent complétés par des levées ponctuelles de matelots ordonnées dans les autres ports du royaume 9 . Ainsi, François Gaiste et Adrien Gournay, marchands du Havre agissant pour eux et leurs amis bourgeois du navire le Saint Richard, commandé par le capitaine Guillaume Maistre du Havre, perdent quatre hommes d'équipage requis en 1656 par la Marine. Les navires forains de passage en Normandie ne peuvent déroger à cette obligation : Jean Locquet de Saint-Malo, capitaine du Saint Louis (350 tonneaux) et André Collinet du bourg de la Chaume en Bas-Poitou, maître de la Cassandre ( 60 tonneaux) doivent fournir chacun six hommes d'équipage à Pierre de Bellegrange, capitaine de la Marine, amiral de l'armée navale et commandant le vaisseau la Reyne en 1654. L'année suivante, outre les levées déjà effectuées au Havre par les capitaines de la Marine Duquesne, Corbière et Daniel, Mathieu Tortreau d'Olonne, maître de la Louise (60 tonneaux), doit s'en retourner à Olonne pour le service du roi. Jean Baudrier, maître du navire l'Espérance d'Abbeville, est lui aussi tenu de se séparer de plusieurs hommes d'équipage pour la Marine ${ }^{10}$.

En revanche, le système de la "presse » (levées par la contrainte de nombreux matelots exigées par l'État dans un port) débouche quelquefois sur des «émotions » urbaines, flambées d'insoumission de ces «mondes rebelles» dans un contexte angoissant de conflits navals, d'accidents climatiques, d'épidémies de peste et de disettes récurrentes ${ }^{11}$. Le dialogue entre la monarchie, l'échevinage et la communauté portuaire prend alors brièvement une tournure violente, dans une province où l'indocilité des gens de mer ressort régulièrement dans les rapports administratifs ${ }^{12}$. Afin d'achever les préparatifs de la flotte à Toulon, le 18 mars 1655 , le roi impose par lettre de cachet à l'échevinage du Havre la levée extraordinaire de 100 officiers, de 400 matelots et canonniers volontaires à retirer des rôles d'armements pour Terre-Neuve. La gronde s'amplifiant sur les quais, l'échevinage dépêche, dès le 24 mars, le marchand échevin Godefroy à Paris auprès du Conseil pour lui signifier l'impossibilité de lever 500 hommes sur un effectif total de 740 officiers et matelots encore en activité au Havre sans gravement désorganiser l'économie locale. Rien n'y fait. Entre le 25 mars et le 5 juin, une deuxième, puis une troisième lettre de cachet, suivies d'un arrêt du Conseil privé du roi, restent sans effet au Havre; les convocations des matelots requis par l'échevinage n'ont pas plus de succès, bien au contraire.

6 Selon le scénario ritualisé des émeutes urbaines ${ }^{13}$, la fronde des marins havrais contraint finalement le lieutenant du roi et l'échevinage, réunis à «l'hôtel commun " de ville, à procéder au tirage au sort des requis dans une atmosphère électrique. Plus de trois mille personnes, dont de nombreuses mères ou épouses de matelots craignant de perdre le bon salaire d'une campagne terre-neuvière ${ }^{14}$, crient au-dehors que les échevins (et non le roi!) sont "des vendeurs de chrétiens ", qu'ils traitent les marins " plus mal en cette ville qu'en Barbarie, qu'on voulait les livrer à la boucherie ». À leur sortie, les autorités locales sont assaillies jusqu'à leurs logis par une grêle de pierres, d'insultes et d'imprécations incendiaires lancées par une populace en furie ${ }^{15}$.

7 L'extrême tension urbaine, observable à travers cette « journée des pierres » du 26 avril 1655 , s'explique d'abord par les lourdes contributions municipales ou royales de toute nature pesant sur la communauté (bien que Le Havre soit exempté de taille). Mais en 
ces temps très rudes pour le commerce maritime et la pêche hauturière, les revendications salariales des matelots et de leurs familles sont bien évidemment au cœur des troubles : « plusieurs hommes ajoutent qu'on les pendrait plutôt que d'aller à la mer à 12 livres par mois [la solde réglementaire dans la Marine], mais que si on voulait leur donner une solde raisonnable, comme l'année précédente, ils seraient tous prêts à s'enrôler ${ }^{16}$. ». L'échevinage du Havre doit même créer un établissement des pauvres valides le 6 juin 1658 pour secourir le nombre élevé d'orphelins dont le père était soldat, matelot ou marinier originaire de la ville ${ }^{17}$. La grande précarité de bien des familles havraises victimes du chômage portuaire rappelle le temps de la Fronde parlementaire en Normandie.

\section{Les errements politiques}

8 Contrairement à ce que l'on pourrait penser, les intérêts des milieux marchands portuaires s'opposent souvent à ceux des entrepreneurs textiles, de mentalité plus protectionniste, et viennent traverser les questions d'ordre politique. La prohibition des textiles anglais décidée par Mazarin en 1648 irrite considérablement les marchands importateurs des ports normands; ils accueillent favorablement en janvier 1649 l'entrée en rébellion du duc de Longueville, gouverneur de la Normandie contre la monarchie "tricéphale» affaiblie ${ }^{18}$. Caen, Dieppe, Saint-Valéry-en-Caux et Fécamp passent en peu de temps sous le contrôle des troupes frondeuses. L'occupation d'Harfleur, Caudebec, Quillebeuf, Pont-Audemer et Rouen par les frondeurs verrouille la navigation en basse Seine ${ }^{19}$. Le duc de Richelieu, gouverneur du Havre, rejoint la Fronde.

9 La rébellion s'effondre pourtant comme un soufflé dans les ports, en raison certes de la campagne militaire du duc d'Harcourt suivie du voyage royal en Normandie en janvier 1650 , mais surtout du fait de la montée des périls maritimes et commerciaux avec l'Angleterre. Le duc de Longueville complote à nouveau en décembre 1651, mais cette fois-ci avec les marchands huguenots dieppois pendant qu'une croisière anglaise patrouille au large. La rumeur d'un débarquement anglais dans la province sème la panique parmi les armateurs, notamment ceux qui sont encore affairés aux derniers préparatifs de la campagne de pêche à Terre-Neuve. Entre-temps, Longueville fait allégeance à la régente et à Mazarin puis fait fortifier en 1652 les ports et le littoral normand contre une éventuelle descente anglaise ${ }^{20}$.

10 En principe représentants directs de l'autorité royale dans une province, les gouverneurs ne se privent pas, durant la Fronde, d'outrepasser leurs fonctions et de se comporter dans leur gouvernement comme de petits souverains, des "petty kings ", au détriment du commerce et de la navigation ${ }^{21}$. Ainsi, l'arrêt du 14 octobre 1650 donné à Bordeaux détaille les abus des gouverneurs et lieutenants des ports, villes et places maritimes : attributions de commissions de capitaines gardes-côtes, maîtres de quai, pilotes, balisiers, interprètes-truchements en lieu et place de l'amiral de France. Les gouverneurs sont aussi accusés non seulement d'empêcher le radoub, l'équipage et l'armement des vaisseaux royaux mais également d'utiliser les poudres, munitions de guerre des magasins du roi pour équiper et armer de leur propre chef des vaisseaux de guerre; ils distribuent sans autorisation des congés et passeports, encouragent les capitaines, maîtres et patrons à ne plus faire de rapports de mer et de visites de navires et empêchent les juges d'amirauté d'exercer leur charge. Bref, "L'audace de ces 
personnes et l'impunité de leurs entreprises, leur rébellion fomentée » occasionnent un grand nombre de désordres en mer et dans les ports, affaiblit l'autorité royale, éteint la charge de grand maître de la navigation, dissipe les magasins du roi, anéantit les forces maritimes du royaume, ruine les vaisseaux du roi, facilite la contrebande et «la surprise des places maritimes [françaises] par le peu de connaissance des forces estrangères que l'on apprend par les rapports de mer $^{22}$ ".

11 L'arrêt reproche de plus à certains gouverneurs ou commandants de place de lever indûment des droits à leur seul profit au grand dam des marchands armateurs. Le gouvernement du Havre est tenu depuis 1650 par la duchesse Marie-Madeleine de Vignerot d'Aiguillon, une nièce du cardinal de Richelieu, «salonnière » avaricieuse et dévote $^{23}$. La duchesse impose de sa propre autorité la levée de droits, effectuée illégalement sur les navires marchands sortant du Havre et y entrant, sans avoir égard aux cris d'écorchés vifs poussés par les marchands rouennais aux états provinciaux de 1655 :

«Ce ne sont pas seulement les Anglois qui persécutent les marchands, les Commandans des Garnisons des Places qui sont en l'emboucheure de la mer, et sur la Rivière de Seine, leur font encore grande oppression. Ils se plaignent en particulier du gouverneur du Havre [la duchesse d'Aiguillon], qui depuis quelque temps, de son authorité, prend sur chaque Navire qui vient du Havre, vingt et vingtcinq escus dont il a fait une ferme, outre les présents et gratifications, dont il a tourné la courtoisie en obligation de nécessité. A l'exemple de ce gouverneur, les Eschevins du mesme lieu, sans aucun droit, exigent dix sols par Tonneau de marchandise qui passe par Le Havre pour venir à Rouen, à l'agravation des Marchands forcez de souffrir que cette exaction passe en compte dedans les avaries des voyages. Mais ils se plaignent en général que les garnisons des chasteaux assis sur la Rivière depuis Paris entrent à force armée dans les vaisseaux qui montent et descendent, pillent et emportent tout ce qu'ils veulent de marchandises sans rien payer et exigent en outre de grosses sommes d'argent. Réprimez, Sire, ces exactions qui causeroient aux marchands plus de naufrage dans vos ports, qu'ils n'auroient couru de hazard parmy les Escumeurs de mer ${ }^{24}$. »

12 Le problème est que la prévarication atteint tous les étages administratifs et militaires de la vie maritime au détriment des échanges maritimes : l'État ne parvient même plus à affirmer son contrôle sur les officiers de la Marine royale. Lors des états de Normandie de 1655, les marchands de Rouen s'indignent de la capture et de la nonrestitution de leurs bâtiments et cargaisons opérées en toute impunité par plusieurs vaisseaux royaux :

«Les Vaisseaux de V. M. ont pris impunément des Navires marchands sortis de vos costes sous les congez de vostre Amiral ; et sur la foy de vos Declarations, vostre Conseil en a receu les plaintes et donné main-levée de telles saisies; Néanmoins elles sont demeurées inutilles par la désobéissance des Commandants de ces vaisseaux : ce qui oblige les Marchands de recourir à vostre Authorité, pour faire délivrer lesdits Vaisseaux et Marchandises si injustement détenües; entr'autres, l'un nommé l'Isabelle et l'autre la Ville d'Estadan, pris par les Navires commandez par le chevalier de Neufchaize, et promenez à la Rochelle, en Broüage, et autres lieux ${ }^{25}$.»

13 Les ordonnances des 27 janvier et premier février 1650 sur les saisies de navires marchands et contre la piraterie ne sont guère suivies d'effet et ajoutent à la confusion administrative régnant déjà dans les ports ou en $\operatorname{mer}^{26}$. 


\section{Un appareil administratif corrompu}

L'affaiblissement de l'autorité publique en Normandie pendant la régence d'Anne d'Autriche complique les opérations marchandes, mais paradoxalement rend aussi de grands services aux marchands portuaires grâce à la duplicité des officiers d'amirauté. Ces derniers, propriétaires de leur charge qu'ils ont acquises au prix fort, s'inquiètent à la fois de la montée en puissance administrative des intendants ainsi que de la possible suppression de leur office et des fructueux émoluments qui l'accompagnent ${ }^{27}$. C'est pourquoi l'émission de passeports et de congés dont le délai d'utilisation est périmé est notoirement facilitée pendant la guerre par la complaisance, voire les complicités ou intéressements, de nombreux officiers des amirautés, tentés par les sirènes de la corruption : les "pots-de-vin » ou autre "tour du bâton », au point de provoquer une inextricable confusion entre navires alliés ou ennemis lors de l'instruction judiciaire de l'amirauté précédant la liquidation des prises :

«Des sujets malintentionnés préférant leurs intérests particuliers a leur honneur propre et à la bonne intelligence que Sa $\mathrm{Ma}^{\text {té }}$ veut entretenir entre ses amis et alliés prennent des commissions daucuns princes allié de Sa Maté et leurs bannières pour faire la guerre a dautres alliés de $\mathrm{Sa} \mathrm{Ma}^{\text {té }}$ quy sont en guerre les uns contre les autres et a la faveur des commissions de France qui leur ont esté accordées la pluspart surannées ou mesme sans pouvoir ny permission vallable font la levéé de leurs équipages es ports de ce royaume qui est une contravention manifeste aux ordonnances $^{28}$. »

15 En réaction, les ordonnances se succèdent à un rythme soutenu pour rappeler laborieusement l'autorité de l'amiral, notamment contre les abus commis dans les ressorts des amirautés proches du front des Flandres (Artois, Picardie et Normandie). Une très active contrebande y prospère lors de la dernière période du conflit francoespagnol car les marchands armateurs normands et picards bénéficient, sans prendre de congé de l'amiral, de passeports espagnols pour les ports flamands afin d'y écouler leurs marchandises :

«Sur l'advis donné a Sa Ma ${ }^{\text {té }}$ qu'aulcuns marchands des villes maritimes et costes de normandie et picardie sous prestexte daffaire la navigation contre les courses des dunquerquois et ostendois, par l'intelligence quils ont avec les sujets du Roy despagne prennent des passeports de ceux qui commandent dans les pays bas et leur en payent de grands destroits mesme sobligent de fournir les places de flandre de vivre denrées munitions et toiles propres a faire voiles et autres marchandises de contrebande et dont le transport est défendu ce qui donne moyen aux ennemis de continuer plus commandement le guerre et est dune dangereuse conséquence au bien de l'Estat tant par la contribution que les ennemis tirent des marchands francois par tels passeports que par linterest de la reputation de la navigation des francois qui se trouve blessée à souffrir que le commerce se fasse par la permission et sous les passeports des officiers et sujets du roy despagne au moyen desquels les marchands francois négligent de prendre les congés et passeports ordinaires $d u$ sieur Grand maître chef et surintendant de la navigation et commerce de France... ${ }^{29}$ ".

La réaction radicale de l'État contre cette fraude, qu'il faut situer dans le contexte de la restauration de l'autorité monarchique, ne se manifeste pas de manière concrète avant l'ordonnance du 15 mars 1659 qui rappelle et réaffirme les ordonnances antérieures ainsi que les sanctions rédhibitoires à l'encontre des contrevenants ${ }^{30}$. La prévarication généralisée ainsi que le laxisme régnant dans les sièges d'amirautés couvrent au-delà de toute retenue les opérations commerciales illicites: 
«Le commerce de quelques commis avec la malice particullière daucuns subjets de Sa Maiesté est venue a tel point pour fuster [échapper] les droits deubz a Sa ditte Maiesté ou nous ou pour oster la congnoissance de leur route charger de Marchandises de contrebande et traffique deffendus par sa ditte Maiesté [...] que nous avons eu plusieurs plaintes et advis des abus et malversations quy se commettoient contre et au préjudice des ordonnances mesme qu'aucuns desdits commis ou fermiers de nos droits pour oster la congnoissance de leur recepte et nous cacher la vérittable valleur des envois desdits passeports sans enregistrement au siège dadmirauté et sans aussy que visittation ait esté faitte ny quil ont esté satisfait aux auttres clauses et condittions desdits passeports et mesme souvent abusant de la facillitté de limpression et distribuans de faux et auttres que ceux que nous leur avons deslivrés et depuis quelque temps en fournissent de différents pour les marchandises et lieux prohibés et pour tous voyages mesme... ${ }^{31} »$.

Est-il besoin de préciser que les "malicieux » sujets en question sont les marchands, armateurs, chargeurs et maitres de navires contraints pour leurs affaires de se prémunir en Manche orientale contre la guerre de course qui est une « continuation du commerce par d'autres moyens»?

\section{La Manche orientale, théâtre de la guerre maritime}

\section{L'exposition préoccupante des côtes normandes}

L'État délaisse, pour des raisons budgétaires, l'entretien comme la défense navale des ports de la Normandie. Les trafics marchands se trouvent de ce fait très exposés aux périls de la navigation et à la guerre de course, notamment lors de la quasi-guerre maritime franco-anglaise de 1649-1655, soulignant la grande vulnérabilité des ports normands. Le chenal d'accès du Havre se comble par accumulation de vases et de galets faute d'un curage régulier (figure 2, ci-dessous). Les échouements et naufrages se multipliant trop fréquemment par gros temps sur les pouliers à l'approche des jetées, les échevins havrais sollicitent en vain l'aide financière de la duchesse d'Aiguillon pour faire "pionner » (curer) le chenal et rétablir les installations portuaires tombées en ruine $^{32}$. En mars 1657 , le bassin à flot du Havre, presque entièrement comblé de vase, est totalement impraticable car « tout menace prompte et entière ruine ». Les jouyères de maçonnerie, le pont levant double de l'écluse et le talus sont écroulés. Les portes rompues de l'écluse ne retiennent plus l'eau à marée descendante. Le ponton de carénage et le " pipery » (radeau de calfatage employé par les calfats) sont détruits. Les autres ports de la Manche se trouvent dans le même état d'abandon faute de fonds, dans une province pourtant réputée pour sa grande richesse ${ }^{33}$. 
Figure 2. Carte des accès nautiques du Havre en 1674

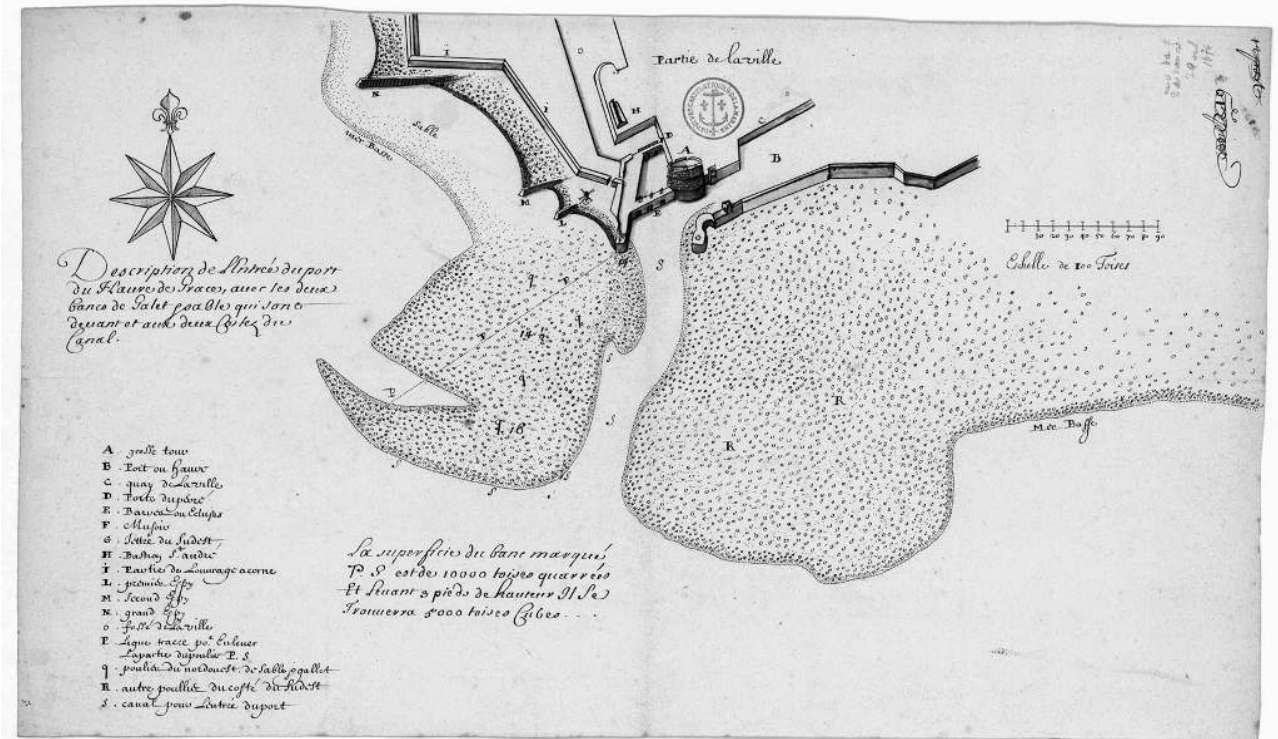

Source : Service Historique de la Défense, Vincennes, fonds Nivart, ms n 144/299, cote : SHD MD07002000 P.

La Normandie étant une province frontière ${ }^{34}$, la protection de ses côtes, de ses ports et de sa navigation contre les armements corsaires ou pirates est évoquée lors de chaque nouveau conflit maritime. Après avoir décidé en 1626 le lancement d'un premier programme de construction de bâtiments de guerre contre la course dunkerquoise, anglaise ou barbaresque ${ }^{35}$, le cardinal de Richelieu anticipe le prochain affrontement avec l'Espagne. Richelieu fait recenser par le commissaire général de Marine Louis Le Roux d'Infreville dans les provinces de la «mer Océane » (le Ponant) le nombre de vaisseaux marchands pouvant être armés en guerre, ainsi que le nombre d'officiers, de matelots et de charpentiers susceptibles d'être mobilisés pour la Marine ${ }^{36}$. Il ordonne également en 1631 la construction de plusieurs vaisseaux gardes-côtes dans des chantiers haut-normands ${ }^{37}$.

Ces bâtiments protègent les trafics marchands en Manche mais les progrès accomplis sont rapidement réduits à néant car Mazarin donne la priorité budgétaire aux opérations militaires terrestres et aux armements de la Marine du Levant ${ }^{38}$. De plus, la plupart des ports et havres de Normandie n'ont pas la fibre corsaire comme Saint-Malo ou Dunkerque et demeurent très mal défendus en cas d'attaque par mer ou sont beaucoup trop éloignés d'une véritable base navale pour bénéficier d'une relative protection maritime en Manche comme le souligne Jean Meyer :

«Mais, au nord-est de Brest, il n'y a plus aucun port français utilisable par une escadre de ligne. On a trop rarement souligné le paradoxe voulu par la nature. La rive nord de la Manche: la côte anglaise offre toute une série de rades foraines assez bien protégées, et de rades admirables comme celle de Southampton; la rive sud n'offre rien, ou pas grand-chose. Car il faut tenir compte des tirants d'eau. ${ }^{39}$ "

21 Le commerce maritime normand se trouve ainsi beaucoup plus fragilisé par la course ou les croisières ennemies que les expéditions opérées par les milieux d'affaires des ports atlantiques. Les trafics de faible valeur ajoutée (pêches, cabotage) ne représentent pas non plus des objectifs stratégiques majeurs pour les flottes de guerre ennemies car les ports de la province sont généralement inaccessibles aux grands vaisseaux de haut 
bord. En revanche, la situation géographique des ports de Normandie proches de l'Angleterre ou de la Flandre espagnole devient critique en raison de leur exposition directe aux raids pirates ou corsaires en Manche comme en mer du Nord ${ }^{40}$.

\section{Le fléau de la course en Manche}

La piraterie locale apparaît quelquefois citée dans les sources mais à mots couverts et à titre anecdotique : nul procès-verbal, aucune enquête ne permet de démonter le ressort d'une entreprise pirate en Normandie, de connaître son port d'armement ou les noms des intéressés durant cette période ${ }^{41}$. Aucun port normand ne réunit d'ailleurs toutes les conditions requises pour devenir une active base pirate ${ }^{42}$. Ainsi, l'armement sous une couverture parfaitement légale de deux frégates au Havre suscite l'interrogation sur ses intentions réelles du fait de la ridicule puissance de feu de leur artillerie ; on est plutôt tenté d'employer le terme de détroussage " au petit pied » pour qualifier ce type organisationnel archaïque d'entreprise de micro-piraterie voué avec certitude à une disparition rapide : "pour ce que telz petitz armemens Sont plustost au desaventage que l'utilité de lestat ne font que Incommoder Les Sujectz et alliez de Sa majesté et leur donnent Le plus souvent occasion de plainctes ${ }^{43}$. ».

Les effets de la guerre de course et de la piraterie étrangère ou de l'embargo sur la navigation normande sont bien plus inquiétants car les corsaires, notamment flamands ou zélandais, multiplient aisément près des côtes les prises parmi les convois marchands ou terre-neuviers mal défendus ${ }^{44}$. Entré au service de Mazarin en 1648, Colbert se montre résolument hostile à la piraterie et à la guerre de course qu'il juge barbares et improductives dans son Mémoire touchant le commerce avec l'Angleterre (1650):

«La sûreté dépend d'une mutuelle correspondance à empêcher les pirates et courses des particuliers, qui, au lieu de s'appliquer en leur navigation à l'honnête exercice du commerce, rompent avec violence le lien de la société civile par lequel les nations se secourent les unes les autres en leurs nécessités ${ }^{45}$. »

La course affecte même l'approvisionnement de monstres urbains du XVII ${ }^{e}$ siècle comme Paris ou Londres, avec les conséquences que l'on imagine pour le maintien de l'ordre public $^{46}$. Ainsi, les autorités de Londres établissent une commission d'enquête en 1630 pour connaître les causes des hauts prix et de la rareté des denrées alimentaires constatés sur les étals. La commission comprend très vite que le défaut d'approvisionnement des Londoniens provient de la suspension du cabotage côtier en mer du Nord due aux corsaires dunkerquois : «Corne, Butter, and Cheese are not brought to this Citty from out of Norfolk, Suffolke, and other parts by Sea as formerly hath beene accustomed for feare of beinge taken by the Dunkerkers as is conceived ${ }^{47}$ ». Un notable effort de protection des convois, notamment des colliers charbonniers de Newcastle, est alors entrepris pendant la Guerre civile puis le Commonwealth de Cromwell. Le caractère hautement stratégique d'une source d'énergie comme le charbon nécessite même, fait exceptionnel en Angleterre, la répartition des frais de convoi sur l'ensemble de la population ${ }^{48}$.

Les différentes estimations des pertes du fait de la course éclairent, même partiellement, l'ampleur de la menace pesant sur les échanges maritimes ${ }^{49}$. Les bénéfices à retirer de la guerre de course expliquent aussi pourquoi des États devenus en principe neutres, comme les Provinces-Unies, soutiennent en coulisse les ports 
corsaires espagnols de Flandre contre l'Angleterre et la France entre 1655 et $1660^{50}$. D'ailleurs, les ports de la Flandre espagnole (Dunkerque, Nieuport, Ostende) constituent le plus actif foyer d'armement en course du milieu du XVII ${ }^{\mathrm{e}}$ siècle au point d'y créer une société maritime originale :

\begin{abstract}
"Meanwhile, Dunkirk, Ostend and Nieuwpoort became the only maritime communities in western Europe since the Viking era in which the violent mass-expropriation of others' property was a respectable avocation, co-existing alongside the more traditional aspects of civil and economic life ${ }^{51} »$.
\end{abstract}

\title{
La Normandie littorale dans le conflit franco-anglais
}

Dépourvue de toute force navale permanente en Manche, la France de Mazarin recourt à l'embargo pour contrer les ambitions économiques de l'Angleterre de Cromwell ${ }^{52}$. Le différend entre les deux pays provient de la décision du Conseil royal de prohiber dès la fin de l'année 1648 les importations de soieries et de draps anglais sous le prétexte de protéger les manufactures du royaume, notamment celles de Normandie et d'île-deFrance. Les textiles anglais déchargés dans les ports de la Manche sont immédiatement confisqués; les commissionnaires anglais établis en France rompent toute correspondance avec les ports anglais par crainte de représailles ${ }^{53}$. Un état de quasiguerre maritime s'installe en quelques mois entre les deux États.

Les armateurs anglais se plaignent de la saisie de leurs bâtiments par les corsaires armés en France sous les fallacieux prétextes de dettes, de contrebande avec l'Espagne ou par simples représailles. Repliés sur leurs bases malouines ou brestoises ${ }^{54}$, les corsaires loyalistes anglais munis de lettres de marque de Charles II fondent sur les trafics stratégiques, notamment les caboteurs charbonniers de Newcastle. Les journaux parlementaires anglais se déchaînent contre ces "pirates", ces «men of forlorn and dangerous fortune [who] thirst daily after blood, having no respect either of friend or foe ${ }^{55}$. Sous la pression conjointe de la Company of London merchants trading in France et de la presse londonienne chauffée à blanc, le «Rump» ou Parlement anglais finit par accepter la délivrance de lettres de marque en juin 1649 puis décrète au mois d'août suivant l'embargo général sur toutes les importations françaises. Pour faire face aux frais de justice prévisibles en France lors du recouvrement des marchandises ou des bâtiments saisis, le Parlement impose aux marchands une taxe exceptionnelle puis impute une contribution prélevée sur les douanes pour financer les convois marchand ${ }^{56}$. En réaction, ces derniers réclament à cor et à cri des navires escorteurs pour leurs navires; ils arrachent enfin auprès du Council of State le déclenchement d'une guerre maritime officieuse contre la France en avril 1650. De leur côté, les marchands des ports français de la Manche accusent les autorités anglaises de tolérer les ventes de leurs navires saisis par les corsaires parlementaires ou de confisquer leurs bâtiments sous le prétexte de contrebande. Les flottes normandes de pêche ou de commerce subissent de lourdes pertes dès la fin de l'année 1650 avec une aggravation du nombre des prises durant l'été suivant. Les bâtiments marchands hollandais, suspectés de transporter des cargaisons françaises sous pavillon neutre, sont à leur tour menacés de capture au titre de l'Acte de navigation anglais d'octobre $1651^{57}$. 

contraint Mazarin à demander l'ouverture de négociations diplomatiques avec l'Angleterre ${ }^{58}$. Le cardinal dépêche à Londres, le 2 décembre suivant, une ambassade confiée à l'intendant de Picardie, Antoine de Bordeaux-Neufville. L'un des objets de sa mission consiste à régler la délicate question des prises et à faire relâcher la pression navale anglaise pesant sur le commerce et la navigation du royaume ${ }^{59}$. Peu confiants dans l'issue favorable des négociations en raison du déclenchement de la guerre anglohollandaise, les députés des marchands normands et bretons exigent de Mazarin des lettres de marque contre les bâtiments ennemis. Ils n'en obtiennent qu'un prudent renouvellement de l'embargo sur les navires et marchandises anglaises car Mazarin veut éviter à tout prix un éventuel rapprochement militaire et naval de Cromwell avec le parti de l'Ormée de Bordeaux ${ }^{60}$.

anmoins, la moyenne course anglaise (bâtiments de 150 à 350 tonneaux puissamment armés) s'en prend à nouveau aux trafics stratégiques des ports bretons, normands et picards au printemps 1653: un convoi composé de 23 terre-neuviers honfleurais est taillé en pièces au début du mois d'avril dans le travers de Cherbourg par une meute de 9 vaisseaux anglais montés d'au moins 45 pièces d'artillerie chacun ${ }^{61}$. Pourtant, une détente toute relative survient entre les deux États. La pression de la course et la demande des marchés deviennent si aiguës des deux côtés de la Manche que les marchands de Dieppe, Calais et Saint-Malo négocient directement en coulisse avec le gouvernement anglais pour relancer les échanges et la navigation. Les petits ports du sud de l'Angleterre mandatent des marchands londoniens pour obtenir la suspension de la course anglaise contre les navires armés à Saint-Malo, en proie à de violentes émeutes anti-anglaises ${ }^{62}$. Afin de ne pas nuire aux lentes et incertaines négociations de paix avec Cromwell ${ }^{63}$, le pouvoir royal exige par lettre de cachet la restitution des navires et marchandises saisis, notamment à Honfleur où des capitaines ont capturé deux petits navires et 25 caboteurs «anglois ou environ faicte soubs prétexte de représailles ou autreman ${ }^{64} 》$.

30 Le traité franco-anglais de Westminster du 24 octobre 1655 (le 3 novembre dans le calendrier grégorien) rétablit les relations commerciales, la liberté de la navigation et prononce la levée des embargos ${ }^{65}$. Une commission mixte devra statuer sur les dédommagements de prises ou de saisies de cargaisons survenues depuis 1640 à accorder aux chargeurs, marchands et armateurs ${ }^{66}$. En effet, le montant estimé des pertes commerciales normandes dues à la guerre de course peu de mois avant la signature de ce traité atteint un niveau exceptionnel, peut-être exagéré à dessein :

«Les Vaisseaux qui sous Commissions de V. M. sont en mer, par les prises de quelques vaisseaux anglois, ont fait juger en Angleterre des représailles sur les nostres; dont les Anglois, depuis peu de temps, ont pris la valeur de plus de cinq millions de livres. Sans représailles mesmes, et depuis un mois, un vaisseau commandé par les ordres du Duc d'York, raudant près de nos costes, s'est saisi d'un Navire chargé de marchandises qui abordoit au Havre ${ }^{67}$. »

31 En dépit des épreuves traversées par les communautés portuaires et littorales comme des graves difficultés commerciales subies par les ports de Normandie, peut-on pourtant parler d'anéantissement du commerce maritime de la province durant cette période? Sans qu'on se départisse d'une lecture toujours prudente des mémoires et autres rapports $^{68}$, le recul, voire l'effondrement, de l'activité portuaire de Dieppe comme des ports cauchois secondaires ne semble faire aucun doute si l'on en croit par 
exemple les rapports de l'amirauté de Saint-Valéry-en-Caux adressés en 1665 à Colbert par l'intendant de la généralité de Rouen, Jean-Baptiste Voysin de la Noiraye :

«II y avoit autresfois [à Saint-Valéry-en-Caux], avant la rupture d'entre les deux couronnes [française et espagnole en 1635], plus de 40 navires de 100 a 200 tonneaux, qui alloient traffîquer aux pays estrangers, outre 18 navires qu'il y avoit pour la pesche des morües. Il y avoit outre cela 18 grands drogueurs qui alloient a la pesche des harangs et maquereaux à Germuth [Yarmouth], et 18 petits bateaux qui faisoient celle qui se faict d'ordinaire au long de la coste. Pour le présent il n'y a plus que 4 petits vaisseaux du port de 40 tonneaux pour le commerce de port en port, ou pour la pesche des morües. Pour celle du harang, il n'y a plus que 3 moyens drogueurs; et à Veule [Veules-les-Roses], il y en a encore, nonobstant le naufrage [la tempête de 1663 dévaste Veules], 18 moyens drogueurs pour la pesche du harang, et 12 petits bateaux qui font la pesche d'au long de la coste. »

Les officiers du siège de l'amirauté de Fécamp déplorent de leur côté la grande décadence du nombre des armements locaux :

«Il y avoit cy-devant dans le port de Fescamp 25 navires qui faisoient le commerce estranger, ou qui alloient de port en port par les costes du royaume y débiter les draps, les serges, les dentelles, et les autres manufactures qui se travailloient dans le bourg dudict Fescamp. Et il y avoit outre cela 20 navires qui alloient à la Terre Neuve a la pesche de la morüe, outre 25 gros bateaux qui alloient à la pesche du harang ; maintenant il n'y a plus aucun navire pour le commerce, ny pour la pesche de la morüe, et n'y reste plus dans ce port que 5 drogueurs pour la pesche du harang ${ }^{69}$. "

Dans un rapport d'inspection de 1665, l'amirauté du Tréport rappelle les malheurs de la dernière guerre maritime qui ont entraîné la perte de vaisseaux marchands et la suspension quasi-totale du trafic maritime local :

«[Le Tréport] a esté d'antienneté fort celebre et bien basty et construit de pallissadde, si estant faict grand commerce qui en a apporté beaucoup de bien et richesses au publicq tant de susdict lieu du tresport que de la ville d'Eu. Lequel traficq a cessé par le malheur du temps de la maladie contagieuse arrivé les années $1619,1636,1647,1648$, que la misere de la guerre qui a toujours continuées ${ }^{70}$. »

La sincérité apparente de ce cortège de lamentations peut susciter un doute légitime, sinon partiel. En effet, la situation varie ponctuellement d'un port normand à l'autre. Certes, les marchands armateurs honfleurais subissent la suspension presque totale de leurs activités entre 1650 et 1652 . La perte de plusieurs navires du lieu s'ajoute à l'interruption de sa navigation due à l'épidémie contagieuse "quy a ravy et moissonné grande nombre et la meilleure partie des principaux habitans » de la ville, après avoir ravagé Saint-Sauveur et la Rivière-Saint-Léonard dont les habitants mis en quarantaine ont dû «se retirer de la conservation du peuple». En revanche, les petits bateaux harenguiers armés "en pêcherie " dans le havre de Veules près de Saint-Valéry-enCaux traversent sans encombre la saison de pêche de 1651-1652 $2^{71}$. De plus, l'exemple havrais suivant montre qu'aucun pays belligérant ne peut économiquement se suffire à lui-même et doit impérativement recourir, même pendant un conflit, aux échanges maritimes pour couvrir ses besoins en produits de première nécessité ou en matières premières selon l'adage anglais : «Speed, need and greed ${ }^{72}$ ». 


\section{La résilience des stratégies marchandes}

\section{Crise ou repli ? L'exemple havrais}

Les statistiques des "submissions" enregistrées à la sortie du Havre mesurent, imparfaitement certes, le repli des trafics portuaires mais ne signifient pas leur disparition complète en raison de la résilience marchande et des stratégies de pluriactivités mises en œuvre, comme le montre l'exemple du marchand armateur rouennais Jacques Regnault. Classé par erreur dans les archives de la juridiction consulaire de Dieppe, le registre 200 BP 35 mentionne 173 actes de «submission » ou certificats de chargement de marchandises à bord de bâtiments marchands, régnicoles ou étrangers, enregistrés à la sortie du bâtiment au greffe de l'amirauté du Havre entre le trois octobre 1653 et le 27 avril 1656. Ces certificats ne sont pas des congés de navigation, ce qui exempte de déclaration certains trafics (pêches, heux et allèges de Seine $^{73}$, navires sortis sur lest) et des destinations lointaines comportant un privilège de commerce et de navigation octroyé en monopole à une compagnie armant par exemple pour le $\mathrm{Canada}^{74}$. Les terre-neuviers ne sont pas non plus comptabilisés dans ce registre ${ }^{75}$. En dépit des réserves émises sur ces sources qui ne permettent pas, loin s'en faut, une approche économétrique aussi sûre que précise, les « submissions » havraises nous renseignent sur des trafics parfois insoupçonnés, et plus généralement sur les interdépendances existant entre l'activité commerciale et les conflits politiques ou militaires.

Graphique 1. Nombre de certificats délivrés au Havre par type de destinations

\section{Nombre de certificats par type de destination}

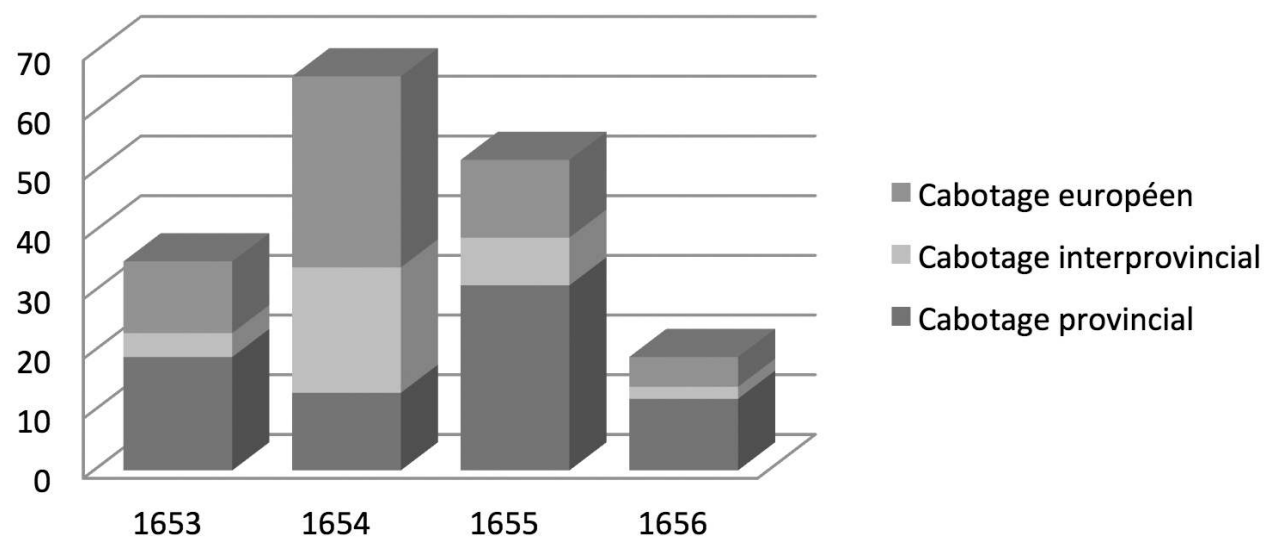

Source : Arch. dép. de Seine-Maritime, 200 BP 35 ; du 3 octobre 1653 au 27 avril 1656. Un acte de 1653 ne figure pas, faute de destination connue. Cabotage provincial : tous les ports de Normandie (Manche orientale exclusivement) ; cab. interprovincial : ports français autres que normands ; cab. européen : tous les ports autres que français.

En premier lieu, la faiblesse du nombre de certificats, donc des sorties de navires, sur l'ensemble de la période allant d'octobre 1653 à avril 1656 peut surprendre au premier abord, même si Le Havre est un port traditionnellement orienté vers les importations et hautement spécialisé dans les armements terre-neuviers ${ }^{76}$. Si comparaison n'est pas raison, Bernard Michon relève pourtant une faiblesse analogue du nombre des affrètements passés à Nantes entre 1650 et 1655 pour l'Espagne ou d'autres 
destinations ${ }^{77}$. Les variations annuelles selon les types de destination confirment les effets de la guerre de course ou de l'embargo en Manche orientale. La redistribution provinciale ou interprovinciale des cargaisons de morues déchargées au Havre connaît un pic en 1653-janvier 1654 (24 actes) avec pour destinations exclusives Dieppe, SaintValéry-en-Somme et Abbeville, avant une brutale décrue entre janvier et septembre 1654 à mettre sur le compte des captures de terre-neuviers havrais. Le mouvement se poursuit avec une remontée des sorties en septembre 1654 et pendant l'année 1655, toujours vers ces mêmes ports ( 15 actes) mais surtout vers Caen ou d'autres ports secondaires de basse Normandie (Isigny, Quinéville, Touques), soit 24 actes de janvier 1655 à avril 1656.

Les variations du nombre des sorties s'observent aussi pour les ports écossais. Outre la persistance de l'Auld Alliance entre la France et l'Écosse par ses réseaux d'affaires, les caractéristiques de la flotte marchande écossaise conviennent idéalement aux faibles frets en temps de guerre maritime ${ }^{78}$. De plus, les ports écossais ont besoin de recomposer rapidement leurs échanges après la campagne militaire de Cromwell en 1650-165179. La guerre anglo-hollandaise de 1652-1654 constitue un appel d'air inespéré pour les pêcheries de harengs écossaises de la mer du Nord fragilisées par la guerre civile $^{80}$. Le blocus anglais des ports hollandais en 1653 suspend les exportations de harengs. Les Écossais ne se privent donc pas d'exporter vers les ports français le produit de leurs pêcheries et d'importer en Écosse des produits alimentaires demandés par un marché de consommation où les salaires ont augmenté ${ }^{81}$. La fin du conflit anglohollandais, l'intégration du royaume d'Écosse au Commonwealth and free State de Cromwell en avril 1654 suivie du soulèvement écossais de Glencairn réduisent ensuite quasiment à néant les relations maritimes avec Le Havre durant la période considérée.

Nombreuses entre novembre 1653 et juillet 1654 (21 actes), les sorties de vins (des clarets bordelais transitent souvent par Le Havre vers Leith qui en importe de grandes quantités), vinaigre, prunes ou autres pots de fer, bougies, papiers, plâtre, chardons à carder la laine pour les ports de Leith, Aberdeen, Montrose, Burnt Island, Queensferry deviennent insignifiantes ensuite ${ }^{82}$, principalement au profit des sorties vers les ports anglais de la côte sud (Topsham, Dartmouth, Lyme Regis, Wight, Portsmouth, Douvres), mais surtout ceux de la côte est, depuis Londres jusqu'à Yarmouth, Boston, Hull et Newcastle-Upon-Tyne (28 actes) ${ }^{83}$. Ces marchandises sont acheminées sous passeport (1653 à 1655) sur des petits caboteurs économiquement et techniquement mieux adaptés à la demande des chargeurs ou des consignataires de la Manche ou de la mer du Nord $^{84}$.

39 La répartition du nombre de soumissions entre les chargeurs et consignataires havrais fait aussi apparaître une disproportion notable entre les milieux d'affaires protestants et catholiques havrais (graphique $\mathrm{n}^{\circ} 2$, ci-dessous). Une forte majorité de chargeurs n'interviennent ponctuellement que pour une, voire deux cargaisons, généralement des céréales, des morues, cuirs, planches, chaudrons ou des vivres d'avitaillement de navires pour les ports de Normandie. Les principaux chargeurs catholiques (Grenier, Grégoire) font embarquer des morues, plus rarement des munitions navales (goudrons, brais) ou des vins pour les îles britanniques (Grenier). Jacques Dacoste ou Dacosta, marchand probablement marrane $e^{85}$, adresse quelques cargaisons de morues pour Isigny mais se spécialise dans les consignations de cargaisons chargées en 1654 sur des bâtiments hollandais pour Saint-Michel de Terceira, Lisbonne ou Bordeaux, indépendamment des cargaisons d'agrumes des Açores reçues de Lisbonne en tramping 
sur des navires marchands anglais, hambourgeois ou, plus rarement, bretons chargés à fret pour Le Havre ou Rouen ${ }^{86}$. Outre la redistribution de morues ou de produits du Nord (graines de rabette, goudrons) vers les autres ports de la Manche orientale, l'essentiel des cargaisons adressées pour l'Écosse ou l'Angleterre est concentré entre les mains des principaux consignataires protestants locaux (Coquemer, Benjamin Duval ${ }^{87}$, Godin...) ou récemment établis (l'Écossais Gilbert Pappe, chargé également des remises de lettres de change pour le rapatriement de prisonniers français $)^{88}$.

Graphique 2. Nombre de certificats délivrés au Havre aux chargeurs et consignataires havrais

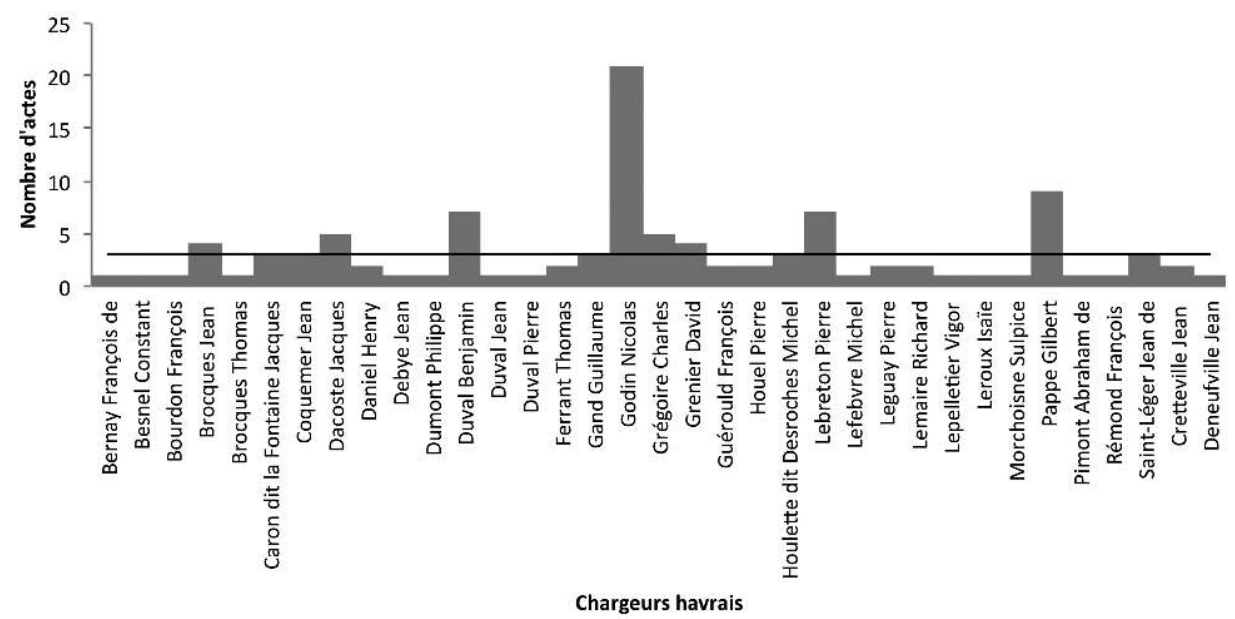

Source : Arch. dép. de Seine-Maritime, 200 BP 35 ; du 3 octobre 1653 au 27 avril 1656

La répartition des ports d'attache des navires révèle également plusieurs informations intéressantes ${ }^{89}$. Le cabotage anglais ( 43 actes de soumission, dont 11 pour la côte sud de l'Angleterre, 9 pour Yarmouth et 8 pour Londres, 12 pour le trio Newcastle-HullBoston) domine les trafics vers l'Écosse ( 12 actes, dont Leith, 5 actes et Aberdeen, 4 actes $)^{90}$. Sans surprise, les trafics vers l'Europe du Nord, la Hollande ou les grands ports français du Ponant (La Rochelle, Bordeaux) sont presque exclusivement effectués par des bâtiments hollandais (10 actes), suédois ( 2 actes) ou hambourgeois ( 1 acte $)^{91}$. Six ports secondaires français se partagent les sorties au cabotage interprovincial : Calais et Saint-Malo (3 actes chacun), Abbeville, Saint-Valéry-en-Somme, Morlaix et Bayonne ( 1 acte chacun). La répartition des sorties des caboteurs normands apparaît fondamentalement dissymétrique entre la prépondérance écrasante des barques et bateaux dieppois (63 actes) dont l'aire de navigation couvre la Manche orientale depuis Isigny jusqu'à Abbeville d'une part, et les petits ports de basse Normandie (12 actes partagés entre Langrune, Bernières, Caen, Quinéville et Barfleur) qui se contentent des simples rotations avec Le Havre, ce dernier faisant presque jeu égal (8 actes) avec son port-jumeau, Honfleur ( 6 actes) d'autre part. Les rares tonnages relevés à la sortie s'étirent entre les 4 tonneaux du bateau dieppois le Don de Dieu de Moïse Gosseaume et les 350 tonneaux du Saint Louis commandé par Jean Locquet de Saint-Malo.

Tableau 1 - nombre de destinations de navires par courtier-interprète havrais

\begin{tabular}{|l|l|l|}
\hline $\begin{array}{l}\text { Courtiers-Interprètes } \\
\text { havrais }\end{array}$ & Nombre d'actes par destinations & $\begin{array}{l}\text { Total } \\
\text { actes }\end{array}$ \\
\hline
\end{tabular}




\begin{tabular}{|l|l|l|}
\hline Chapelle Jacques & Bordeaux (1) & 1 \\
\hline De Cretteville Jean & Calais (1) & 1 \\
\hline De Cretteville Pierre & Middelbourg (1), Leith (1), Saint-Malo (1), La Rochelle (1) & 4 \\
\hline Deneufville Jean & Newcastle (1), Londres (3) & 4 \\
\hline Deneufville Pierre & Leith (1), Yarmouth (1), Lyme (1), Hull (1) & 4 \\
\hline Frecquet Charles & $\begin{array}{l}\text { Newcastle (1), Leith (1), Aberdeen (1), Hull (1), Londres (1), } \\
\text { Boston (1) }\end{array}$ & 6 \\
\hline Lecordier Pierre & La Rochelle (1), Nantes (1) & 2 \\
\hline Letournois Nicolas & $\begin{array}{l}\text { Newcastle (1), Wight (1), Leith (3), Aberdeen (2), Hull (1), } \\
\text { Dartmouth (2), Saint-Jean-de-Luz (1) }\end{array}$ & 11 \\
\hline Letournois Philippe & Londres (1) & 1 \\
\hline Total & Ports français : 7 actes ; ports britanniques : 27 actes. & 34 \\
\hline
\end{tabular}

Source : AD 76, 200 BP 35 ; du 3 octobre 1653 au 27 avril 1656

41 Enfin la répartition des 34 actes du nombre de destinations de navires sortis du Havre recourant aux services d'un des 9 courtiers interprètes locaux (tableau 1) fait apparaître un déséquilibre marqué entre un petit groupe spécialisé dans le truchement avec les maitres venus des ports anglais ou écossais et composé de Nicolas Letournois (12 actes), Charles Frecquet ( 6 actes) Jean Deneufville ( 4 actes) et leurs collègues dont les destinations des actes ressortent de manière plus diversifiée et surtout plus occasionnelle.

Inutile d'insister plus longtemps pour mettre en évidence le repli fortement prononcé $\mathrm{du}$ commerce maritime havrais ${ }^{92}$, sans toutefois confirmer le marasme parfois abusivement avancé comme prétexte pour des motifs fiscaux ${ }^{93}$. L'armement havrais au cabotage demeure aussi inexistant qu'en 1627 face au "géant» dieppois ${ }^{94}$. Si l'on excepte la redistribution provinciale des cargaisons terre-neuvières inévitablement affectées par la guerre maritime, l'étroite structure socioéconomique du commerce en commission havrais, de type passif et totalement dominé par les marchands ou les chargeurs d'autres places de commerce, ne connaît guère d'évolution par rapport aux décennies précédentes ${ }^{95}$. D'ailleurs, les « submissions » soulignent en creux le problème de la «monoculture » terre-neuvière havraise plaçant l'activité portuaire en un dangereux porte-à-faux dès le déclenchement d'un conflit maritime, sans que le négoce de place rouennais puisse efficacement soutenir le commerce en commission du Havre. Comprenant tout l'intérêt d'une diversification commerciale, les Havrais observent très attentivement l'établissement des compagnies de commerce de Colbert au Havre au début des années 1660. Mais la question demeure : le problème commercial structurel du Havre, aussi observable à des degrés divers dans les autres grands ports terreneuviers de la Manche depuis Saint-Malo jusqu'à Dieppe, est pourtant ignoré à Bordeaux « ville bonne et riche » et très probablement aussi à Nantes, deux ports qui arment pourtant vers Terre-Neuve, et où les négociants retirent de bons profits lors de 
la décennie 1650 grâce à leur symbiose avec les réseaux hollandais et hambourgeois ${ }^{96}$. Pour le marchand havrais, la lente accumulation capitaliste par la marchandise en temps de guerre maritime passe bien avant l'armement de navires, mais comment la préserver?

\section{Les modes opératoires marchands particuliers}

La précaution a minima d'un marchand pour échapper à la saisie de sa cargaison en mer comme à terre consiste à dissimuler habilement la provenance de ses marchandises, voire de la dissocier sans conteste du pavillon du navire. Un mémoire des marchands rouennais de février 1657, retranscrit par le conseiller Robert Bigot de Rouen, expose leurs revendications au moment où le parlement de Normandie délibère sur l'interdiction d'utiliser des bâtiments étrangers pour le cabotage de port à port dans la province ${ }^{97}$. Plusieurs parlementaires avisés défendent pied à pied cet indispensable recours de la navigation du temps de guerre. Bigot justifie le point de vue marchand en affirmant que «lon Voioit grand nombre de famille considerables que la difficulté du Commerce avoit depuis quelques années extraordinairem[ent] Incommodé ». Le projet d'interdiction est finalement rejeté à une courte majorité :

«En ce temps ou le malheur veut que l'on ne negotie que sur des navires Empruntés, \& sous ce nom de nos alliéz, mesme pour faire le traffic des affaires de france les Unes avec les autres co[mm]e de Normandie En Bretagne, de Bretagne En Gascogne \& de ces lieux la L'on est obligé de se servir des Navires Hollandois \& Hambourgois, Et ce seroit une precaution bien Inutille \& tres dangereuse si on Estoit obligé de registrer les cognoissements \& les chartes parties ${ }^{98}$.

Les questions de nationalité n'ont pas non plus cours parmi les marchands là où gisent de fructueuses perspectives de profit ${ }^{99}$. Les marchands armateurs comme les chargeurs normands s'accommodent sans vergogne des affrètements neutres, voire ennemis, souvent trouvés en Normandie à bien meilleur marché que le taux de fret national, afin de poursuivre les échanges dès la moindre menace d'insécurité sur les mers ${ }^{100}$. L'intermédiaire hollandais ou hambourgeois relève même de la plus impérieuse nécessité101, mais au risque de se faire saisir ses marchandises "contre l'équité naturelle ${ }^{102}$ ». En effet, le moindre ballot d'origine suspecte et chargé à bord d'un bâtiment marchand lors d'une escale suffit souvent à justifier la saisie du navire et de sa cargaison lors d'un arraisonnement corsaire en haute mer. C'est pourquoi les États de Normandie de 1655 réclament un ajustement plus souple de la législation maritime :

« Nous demandons que la Robbe ennemie, qui par l'usage de la Marine fait perdre la Robbe de amy, ne s'entende que du Vaisseau qui enserre la marchandise; en sorte qu'elle soit traitée comme ledit Vaisseau, et que le mélange qui se pourroit trouver de quelque ballot de marchandise défendue dans un vaisseau chargé à cueillette, ne fasse pas perdre toute la charge ${ }^{103}$. ».

Lors de la guerre franco-espagnole (1635-1659), les marchands rouennais chargent aussi leurs marchandises sur des navires anglais pour en éviter la prise par les corsaires flamands, en dépit des sérieuses complications juridiques à prévoir en cas de prises survenues durant la Guerre Civile anglaise (1642-1651) entre navires royalistes anglais et bâtiments armés par des partisans de Cromwell. Les marchands adaptent aussi la géographie de leurs réseaux d'approvisionnement et de transport. Afin de réduire les risques de saisie des cargaisons par la course ou la piraterie, les ballots de laine d'Espagne adressés à Rouen pour alimenter le grand bassin drapier du nord de la France sont déroutés vers Nantes pour gagner la Normandie via la Loire et le canal de 
Briare mis en service en 1642 , au lieu de transiter par les ports de la Manche plus exposés à la guerre maritime ${ }^{104}$.

Les voyageurs anglais, en petit nombre, qui débarquent à Saint-Malo, Dieppe et Rouen $^{105}$, les correspondances d'affaires passant par Calais, Boulogne, Douvres, Gravesend ou Rye ainsi que la presse tiennent au jour le jour les marchands informés des expéditions de marchandises ${ }^{106}$. La présence de colonies marchandes étrangères dans les grands ports normands (Rouen, Dieppe) facilite bien évidemment les échanges dissimulés avec les ports anglais. Très impliqué dans le commerce normand avec Londres, le marchand anglais Jean Part ou John Parr s'est établi à Rouen où il meurt en $1651^{107}$. Le marchand londonien John Paige, l'un des plus grands négociants du Canary Trade (vins de Ténériffe), est en correspondance en 1649 avec David Congnard du Havre, le frère du marchand rouennais Nicolas Congnard, ou Humphrey Wilkings de Rouen qui prend acte en 1651 de la vive concurrence commerciale des ports atlantique français au détriment de Rouen ${ }^{108}$. Ces marchands étrangers proposent en commission des services complémentaires aux chargeurs régnicoles : assurances, crédit commercial, passeports ou affrètements de navires :

«Les navires et vaisseaux estrangers chargent les marchandises du royaume dans les ports de france mesme privativement aux vaisseaux francois dont les capp ${ }^{\text {nes }}$ maistres patrons et marchands de la plus grande partie des portz de france ont fait diverses plaintes et de ce que par les caballes et intelligences que lesdits estrangers entretiennent depuis longtemps dans lesdits portz ils se rendent préférables pour le fret aux francois ce quy non seullement tourne a la perte des $\mathrm{pa}^{\text {ers }}$ marchands propriéttaires des navires francois quy faute demploÿ sont obligez de quitter mais encore déserte les portz de grand nombre de pillotes canonniers et matelots francois quy vont chercher leur subsistance ou le nombre des navires et plus grand $^{109}$.»

Humphrey Wilkings sollicite également ses relations proches du pouvoir royal à Whitehall pour tenter de récupérer les navires marchands français détenus en Irlande ou en Angleterre. ${ }^{110}$ En dépit des critiques récurrentes des marchands régnicoles accusant les marchands étrangers d'accaparer les trafics portuaires les plus fructueux, les commissionnaires étrangers ont recours à la navigation française: le marchand anglais Humphrey (ou Winfray) Wilkings établi à Rouen affrète au capitaine havrais Nicolas Oursel son navire la Catherine de 100 tonneaux pour se rendre en droiture depuis Rouen pour charger à fret du charbon de terre à Limkils (Limekilns en Écosse) et faire son retour directement à Rouen. Le chargement passe sous pavillon neutre puisqu'il s'effectue officiellement pour le compte du marchand écossais Williams Bruce de Rotterdam ${ }^{111}$.

Une entente sur la base d'une confiance réciproque en affaires est souvent convenue entre marchands en cas de capture d'un navire pour éviter les frais de procédure de liquidation de prise, le paiement du droit du dixième du montant des prises à l'amirauté, ainsi que le dépérissement du chargement: c'est ce que l'on appelle la " recousse ${ }^{112}$ ». Une cargaison chargée à Rouen par le même Wilkings en avril 1652 sur une barque de Tapson (Topsham) commandée par Richard Stevenson est prise par la double chaloupe du pirate français Saint Sauveur, lui-même ensuite capturé puis dirigé avec sa prise au Havre par la frégate garde-côte du capitaine Thomas Stalin. Jacques Regnault, l'armateur rouennais de la frégate, s'entend rapidement avec Wilkings sur le montant de l'indemnité à recevoir pour la mainlevée de la barque et de son chargement après un avis circulaire donné aux différents chargeurs ${ }^{113}$. 

portuaire et maritime engendrée par la guerre de course en Manche. Lorsqu'un trafic stratégique comme celui des beurres et cidres de basse Normandie est directement menacé, les grands marchands de Paris se montrent à leur tour capables d'imaginer une riposte collective privée en finançant conjointement l'armement de petites escadres côtières de protection des convois de caboteurs en Manche orientale en lieu et place de l'État à qui incombe ordinairement cette mission ${ }^{114}$.

\section{La pluriactivité commerciale de Jacques Regnault à l'enseigne du Mouton Rouge à Rouen}

En ces temps de mondes rebelles, les communautés marchandes européennes apprennent à s'organiser face à l'économie de prédation, par exemple à Londres en finançant les troupes parlementaires ou les armements en course durant la Guerre civile $^{115}$. À Paris, les marchands de la Halle et les marchands épiciers interviennent eux aussi contre la course maritime en Manche car le total des fonds engagés chaque année en Normandie pour le ravitaillement de Paris l'exige ${ }^{116}$. Proies faciles à capturer pour les corsaires flamands ou les pirates barbaresques ${ }^{117}$, les terre-neuviers havrais ou les caboteurs bas-normands doivent alors naviguer en convoi, mais au prix d'une protection tarifée "à l'entreprise ${ }^{118}$ ». Dans le très informatif extrait infra, les marchands de Paris, de Rouen et d'Isigny font, au cours des derniers mois de la guerre de Dévolution, le siège du duc de Saint-Aignan, gouverneur du Havre, pour trouver un armateur capable d'assurer la protection des convois côtiers de basse Normandie, tout en insistant sur leur caractère stratégique vital pour l'approvisionnement de Paris :

«Il seroit tres nécessaire pour le bien du Commerce davoir au Havre de grace deux ou trois moyennes fregattes armez en guerre, pour netoyer la coste de normandie des petits bastiments ostandois quy y sont journellement pour prendre les navires marchands. Lesquelles fregattes serviroient à escorter conduire et raconduire lesdits navires marchands qui vont de port en port et voiturer des marchandises et les garantir de linsulte des ennemis, qui se tiennent dordinaire proche de terre pour surprendre les navires marchands a laproche des ports, et pour esviter la rencontre des Vaisseaux du Roy qui se tiennent plus esloignez a cauze de leur grandeur qui ne leur permet pas daprocher les costes, et qui sont dailleurs tres necessaires dans le canal de La manche pour donner la chasse aux grands Vaisseaux ennemis quy y sont. De sorte que ces moyennes fregattes seroient dune tres grande Utillité aux marchands quy pouroient sans discontinuation faire leur Commerce et envoyer leurs Vaisseaux sans retardement et avec plus de seuretté, et qui ne sacableroient pas par les assurances quils seront obligez de faire pour ne pas tout risquer, et qui augmente Infiniment le pris des denrez et est extremement a charge au publicq. Et par ce moyen lentrée de la Rivière de Seine qui recoipt touttes sortes de vaisseaux chargés de marchandises et provisions pour paris Et la meilleure partie de la France, seroit a Couvert de linsulte des ennemis, mesme le reste de la Coste de normandie, comme Caen, Cherbourq, issigny, \& autres ports, et les marchands espiciers de paris favorisez en leur negosse de beure quils font venir desdits lieux pour la fourniture de paris, lesquels lors de la guerre derniere avec lespagne avoient traitté avec des particuliers pour entretenir pareil nombre de Vaisseaux, et sont presentement aux recherches pour en trouver, sans quoy difficillement, Ils pouront continuer leurs négosse ${ }^{119}$. "

51 L'organisation de la protection navale des convois de basse Normandie devient au cours des années 1650 l'affaire du marchand armateur Jacques Regnault de Rouen (1609-1691) qui n'est plus un novice en la matière ${ }^{120}$. Il faut d'ailleurs reconnaître à cet habile 
armateur rouennais une réelle capacité à monopoliser entre ses mains le marché privé de la coercition maritime en Normandie contre le faux saunage ou la guerre de course avec les traitants des gabelles, les armateurs de la pêche au hareng et les milieux marchands ${ }^{121}$. Sans revenir ici sur son autobiographie controversée ${ }^{122}$, le choix de cet armateur par les marchands de Paris, Rouen et de basse Normandie s'explique par les caractéristiques particulières de son réseau placé à la croisée des chemins avec l'armement dieppois (Jacques Baudry, Jacques de Caux père \& fils), ses liens d'affaires avec la Hollande par les marchands Jean Rasse, Pierre Cossart et Jean Hamsincq de Rouen, la Marine royale, le monde des financiers intéressés à la compagnie de la Nouvelle-France, de la banque et du grand négoce de Paris par son mariage avec Louise Hazon, d'Orléans, après $1635^{123}$. Si ses liens d'affaires avec le clan anglo-dieppois des frères Kirke restent à prouver, un faisceau d'indices montre que Regnault entretiendrait aussi des correspondances fort opportunes en Angleterre devant la commission des prises par le biais du sack trade et de l'achat de cargaisons morutières anglaises déchargées au Havre ${ }^{124}$.

Durant la guerre maritime, Regnault juge plus prudent de diversifier ses affaires par une stratégie de pluriactivité commerciale ${ }^{125}$. Il poursuit tout d'abord ses prises de participation dans des navires ${ }^{126}$. Deux acquisitions lui causent d'ailleurs bien du tracas pendant l'année 1651 : le heu de 70 tonneaux qu'il se fait adjuger à Ostende par l'entremise de Jacques Le Jenne de Rotterdam se fait capturer à la sortie de ce port par des barques de Calais commandées en course par le précédent capteur du heu, le capitaine Charles Roussel de Boulogne ${ }^{127}$. Après avoir vendu au Havre sa flûte le Mouton rouge de 250 tonneaux, l'armement en Hollande de sa nouvelle acquisition, la Pucelle d'Incuize, traîne en longueur et à grands frais au moment où s'annonce la guerre anglohollandaise $\mathrm{e}^{128}$. Soucieux de diversifier constamment ses profits, Regnault prend aussi à bail la ferme des droits d'ancrage et de congés en Normandie au nom de l'amiral César de Vendôme ${ }^{129}$. Jacques Regnault s'appuie dans chaque port sur des marchands sûrs à qui il donne sa procuration (par exemple Guillaume Levasseur de Dieppe, Vincent Pimont le jeune de Saint-Valéry-en-Caux, Jacques Toustain de Caen) pour percevoir les droits de l'amiral, tout en rendant compte des adjudications de prises adressées par ses bâtiments armés en guerre.

Regnault sait en effet que la guerre maritime peut également lui offrir de nouvelles opportunités de profit. Il conclut son premier marché le 27 juillet 1649 avec François Guymont, commis général des gabelles en Normandie. Ce dernier veut en finir avec la fraude maritime des sels qui est endémique entre le Cotentin, placé sous le régime fiscal avantageux du quart-bouillon, et le reste de la Normandie assujetti à la grande gabelle. Regnault fait d'abord armer la barque le Saint Pierre de 20 tonneaux, commandée par Jacques Du Parcq en 1650 puis par Hélye Perquier l'année suivante pour une patrouille permanente le long des côtes normandes ${ }^{130}$. La mesure se révélant insuffisante, Regnault passe en 1652 un nouveau marché d'affrètement avec les fermiers des gabelles pour sa frégate le Lévrier de 50 tonneaux, 6 canons et 4 pierriers, commandée par le capitaine de la Marine Jean Mahier ou Mayer du Havre pour "l'empeschement du faux saunage ${ }^{131}$ ». En 1656, les grands moyens sont déployés contre la fraude par des proches de Mazarin associés dans la compagnie de la NouvelleFrance : les marchands banquiers et financiers Pierre et Claude Girardin frères de Paris, qui viennent de succéder à Jacques Datin dans le bail de la ferme des gabelles. Ils contractent en février 1656 avec Jacques Regnault l'armement à Dieppe de trois 
vaisseaux de 80 à 100 tonneaux montés chacun par 30 matelots et 30 soldats afin d'éradiquer la piraterie, la course, saisir les bâtiments qui «auront ou apporteront marchandise de contrebande" et escorter les bâtiments marchands en Manche orientale ${ }^{132}$.

En dépit des inconvénients liés au système des convois marchands ${ }^{133}$, la nécessaire protection navale des caboteurs des beurres et cidres le long des côtes de la basse Normandie représente un autre segment d'affaires profitable pour Jacques Regnault depuis son premier contrat d'affrètement de deux frégates et une double chaloupe passé le trois août $1646^{134}$. Les parties en présence dans les contrats d'affrètement de frégates d'escorte varient selon le degré de confiance ou les liens familiaux existant entre les marchands chargeurs des ports de basse Normandie, Jacques Regnault, les capitaines entretenus et les marchands parisiens.

Dans le premier cas, Regnault et plusieurs marchands des ports et havres bas-normands (Isigny, Carentan, Saint-Fromond, Barfleur, Port-en-Bessin et la rivière de Caen) s'entendent par contrat pour l'escorte des caboteurs de cidres, poirés et autres marchandises entre les ports du Bessin ou du Cotentin et la Seine. Ce marché stipule l'armement en guerre d'une frégate de 10 canons et 50 hommes d'équipage, commandés par le capitaine Thomas Stalin depuis le mois de janvier 1652 jusqu'à la fin du mois d'août de la même année. Le vaisseau escorte à l'aller les gribanes, barques et bateaux depuis les rades du Havre et d'Honfleur vers les ports bas-normands avec leurs futailles vides affrétées par les maîtres gribaniers auprès des marchands de cidres hautnormands dès que le nombre de 6 à 8 bâtiments sera atteint en rade. Le retour s'effectue toujours en convoi depuis Isigny, Carentan, Port-en-Bessin et l'estuaire de Caen vers Rouen ${ }^{135}$.

Marchands d'Isigny, Saint-Fromond, Carentan, Barfleur, Port-en-Bessin et Caen signataires du contrat du 15 décembre 1651: Dieppedalle, Daubin, Pierre Gommet, Duquesné, Pierre Morel, Varigon, Jacques Tabouret, Sallux, Pierre Daubin, Jacques Nepveu, Pierre Julianne, François Gardenbas, Jouenne Boudé, Picquenard.

Dans le second cas, le contrat d'escorte est cette fois directement conclu entre Jean Mahier, capitaine entretenu de la Marine du Havre, résidant à Rouen rue de la Vicomté mais logeant pour l'occasion à Paris chez un proche, le marchand Jacques Mahier, d'une part et Jacques Plansson, marchand épicier de Paris rue de la Cossonnerie à l'enseigne du " griffon d'or ", aussi établi à Isigny rue des Dames, constitué représentant des élites marchandes de la capitale (épicerie, négoce des cidres et vins) ou de Normandie, certains appartenant aux Six Corps de Paris, d'autre part ${ }^{136}$. 
Marchands de Paris, Saint-Denis, Rouen et autres lieux signataires du contrat du 8 juin 1656 et du contrat du 5 avril 1656 prorogé : Jacques Plansson (marchand épicier élu consul des marchands de Paris en janvier 1659), Anthoine Frémeau, Jacques Dours, Claude Devin, Denis Langlois, Denis Le Laboureur, Mathurin Niceron père et fils, Vincent Hébert, Nicollas Drouet, Pierre et François Miquyel, Fidélie Le Marchand, Louis Niobet, Thierry Mésager, Jean Nottin, Pierre Baronneau, Jean Ledoulx, Nicollas Gerie, Christophle Vintaut, Daniel Nepveu, Claude et Thomas Dedessus le Moustier \& Cie, Claude Plansson, Guillaume Montier, Arthur Pierre, Claude Ollivier, Anthoine Delamare, Thomas Lefebvre, Louis Berthault, Pierre Corchin, Charles de la Roze, Elisabeth de Paris veuve de noble homme Pierre Eustache ex-échevin de Paris, Margueritte Guillemot veuve de Michel Raguenet, Elisabeth Thorentier veuve de Guillaume Guillebon, Barbe Bourdin veuve de Louis Lancel, François Legrand, Louis Bellin et Margueritte Guillier veuve de Jean Thouret, tous marchands de Paris; s'y ajoutent par prorogation du contrat du 5 avril 1656: Jean Bouchard, Margueritte Martin, Nicollas Simon, Claude Quérel, Nicollas Denis pour Nicollas Richel, Jean Duchemin, Jean et François Delacour frères, Nicollas Bourdon, Adrien Goudes, Berthélémy Lenoir, Anthasne de Baize, Clément Duhamel, François Turpin, Hugues Coppin, Estienne Langlois, Guillaume Pierre, de Montqueron, Guersent, Delabisse. consuls de Paris, les marchands affréteurs conviennent du prix de la protection de leurs convois avec le capitaine Jean Mayer ou Mahier cautionné par le capitaine et échevin havrais Adrien Godefroy de Nipiville (logé chez Bobeline, rue grande Truanderie à Paris). Le capitaine Mayer prend à sa charge les frais d'armement, victuailles, salaires, armes et munitions des deux vaisseaux la Vierge (10 canons, 60 soldats et matelots), la Saincte Genefviève (8 canons, 40 hommes) et de la barque longue la Saincte Elizabeth (2 canons, 20 hommes) appartenant à Regnault.

58 Les deux premiers vaisseaux doivent se trouver en juin 1655 à Port-en-Bessin prêts à convoyer la flottille des caboteurs jusqu'à Honfleur, puis repartir en droiture pour Isigny. Son correspondant, le marchand Claude Martin d'Isigny, remettra au capitaine Mayer la liste des bâtiments qui ont acquitté le droit de convoi et venant de SaintFromond, Carentan, Sainte-Marie, Quinéville, La Hougue et autres lieux circonvoisins. Mayer est ainsi tenu jusqu'au 31 décembre 1655 de protéger les convois entre Port-enBessin ou Isigny et l'estuaire de Seine, tout en étant autorisé à poursuivre en course les vaisseaux ennemis tant que l'état de la mer le permettra. En cas de perte, prise ou naufrage, il ne sera rien dû par le convoi au capitaine. Le contrat est reconduit le 5 avril 1656 mais désormais réduit à deux vaisseaux commandés par Adrien Godefroy de Nipiville car Jean Mayer profite de la reprise des échanges maritimes pour prendre en 1658 le commandement d'une campagne terre-neuvière sur l'Aurore du Havre ${ }^{137}$. Pour sa part, Regnault reçoit de l'amiral de France la charge de commissaire du roi pour la Marine dans le département de Rouen. En revanche, son ascension sociale continue reste un cas relativement isolé dans le milieu marchand.

Comment un marchand armateur peut-il persévérer dans ses affaires en Manche orientale durant la décennie 1650 en dépit des mille et un tourments qui le guettent? ${ }^{138}$. Les marchands des ports normands se heurtent aux difficultés de toutes natures (politique, corruption, tension sociale) venant s'ajouter aux périls de la piraterie ou de la course maritime. L'exemple statistique havrais souligne l'important repli des trafics 
à la sortie durant la quasi-guerre avec l'Angleterre. Néanmoins, les échanges commerciaux par cabotage ainsi que les armements de pêche sont maintenus vaille que vaille en Normandie car les États et les marchés de consommation du nord-ouest européen ne peuvent se passer du commerce extérieur pour leurs approvisionnements, même en temps de guerre.

Afin de maintenir l'interaction portuaire et commerciale durant les conflits maritimes de la période considérée, les marchands normands font preuve d'une grande capacité de résilience par la pluralité commerciale, le contournement des interdits réglementaires, l'organisation des convois marchands, l'emploi habile de toutes les ressources possibles de la neutralisation ou de la dissimulation du pavillon du navire et de la marchandise ; nul ne les blâmerait d'ailleurs en ces temps turbulents, mais pour quels résultats?

61 La mise en perspective des ports français du Ponant montre que la décennie 1650 représente une étape majeure pour les milieux marchands. Ceux de Bordeaux continuent les armements terre-neuviers ainsi que les exportations de vins vers l'Angleterre au moyen d'un très actif cabotage. Les armateurs de Nantes et Saint-Malo poursuivent certes leurs trafics traditionnels de pêche ou de cabotage ; certains d'entre eux commencent pourtant à s'intéresser de près au commerce en droiture avec l'Amérique. Mais en Normandie, la réorientation des trafics vers le commerce antillais apparaît bien trop aléatoire aux marchands armateurs en raison de la proximité anglaise, de la présence très concurrentielle des Hollandais aux Antilles et de la guerre de course récurrente en Manche. De plus, la faiblesse numérique des marchands normands impliqués dans le commerce antillais empêche l'émergence en Normandie d'un groupe entreprenant de New Merchants comme en Angleterre ${ }^{139}$.

62 En bonne logique entrepreneuriale, les marchands de Rouen, de Dieppe et de Caen conservent leurs activités habituelles de pêche ou de cabotage tout en accentuant leurs échanges commerciaux avec les ports anglais de la Manche et de la mer du Nord dont ils retirent des profits accrus au moins depuis le traité de Westminster de 1655. L'augmentation du nombre des consignations de marchandises adressées vers les Îles britanniques est d'ailleurs à l'origine d'une grogne croissante des marchands londoniens contre la France: "whereby their nation becomes enriched and ours impoverished ${ }^{140} »$. Plusieurs grincheux de la City s'inquiètent ouvertement de la vigoureuse offensive du commerce français à l'origine d'une polémique grandissante à Londres en raison du déficit inquiétant de la balance commerciale anglaise ${ }^{141}$.

Ce faisant, les marchands des ports de Normandie prennent également conscience pendant la guerre maritime que leurs activités commerciales et maritimes dépassent le strict cadre de leur enrichissement individuel ou de leur élévation sociale en contribuant davantage au "bien commun» du royaume ${ }^{142}$. Ainsi, durant les années 1650 , le sentiment naissant de "l'honneur marchand " contredit le préjugé nobiliaire envers la "vile bourgeoisie», en s'exprimant par exemple au détour d'un contrat rédigé par des marchands de Paris et d'Isigny dans lequel ils tiennent à "rendre les combats que gens de cœur et dhonneur doibvent rendre a lencontre des Ennemis et Pirates de mer $^{143} »$. 


\section{NOTES}

1. «Nous vivons sauvagement/Et donnons avec largesse/Ce que le Ciel nous octroie./ Nous ne sommes pas nés/Pour le travail et le commerce/Où s'acharnent tous les fous ».

2. O lHMEYER, Jane H., " "The Dunkirk of Ireland": Wexford privateers during the 1640s' ", Journal of the Wexford historical Society, 1988-1989, n 12 , p. 23-48 : Wexford est, loin devant Waterford et Kinsale, la grande base corsaire irlandaise présentée en 1649 par la presse anglaise comme "the Dunkirk of Ireland, and a place only famous for being infamous", les corsaires irlandais allant souvent liquider leurs prises à Dunkerque. WILDBRIDGE, Thomas T., The Hull Letters, Hull, Wildbridge \& Co, 1884, p. 107 : «We have likewise newes that 7 shipps ladened with armes etc. coming from France going to the Irish rebels were taken by our shipps.", lettre de Peregrine Pelham du 23 septembre 1645. OlHMEYER, Jane H., "Irish privateers during the Civil War, 1642-1650", The Mariner's Mirror, 1990, vol.76, $\mathrm{n}^{\circ}$ 2, p. 119-134: la course irlandaise a capturé au moins 250 bâtiments entre 1642 et 1650. MURPHY, Elaine, Ireland and the War at Sea 1641-1653, Woodbridge, The Boydell Press, 2012, p. 151-221.

3. Nouveau Glossaire nautique d'Augustin Jal, Paris, 2011, CNRS éd., lettres NOP, p. 1583 : une pinasse est un " petit vaisseau long, étroit, à l'arrière carré, gréé en trois mâts ».

4. Bibliothèque nationale de France (désormais BnF), ms fr. 16565, fo $69-70$ : factum pour Gilbert Pappe, David Grenier, etc., postérieur au 7 avril 1645. Les armateurs Gilbert Pappe, David Grenier, Geoffroy Le Tournois, Richard Aubin \& $C^{\text {ie }}$, sont tous marchands du Havre. La barque est armée au Havre et en est partie en mars 1644, commandée par Nicolas Le Ducq; le commis subrécargue est François ollivier. Le bâtiment havrais touche Wexford en Irlande, y écoule sa cargaison puis, avec le profit réalisé, achète et charge des produits du cru ou d'Amérique. Envoyé à Plymouth, l'interprète havrais Nicolas Le Tournois n'obtient rien du comte-amiral Varouicq (Warwick). Sabran, l'ambassadeur de France à Londres, porte en vain l'affaire devant le Parlement anglais, dont certains membres sont directement intéressés dans le corsaire de Rawle.

5. W ILSON, Charles, England's apprenticeship 1603-1763, London, Longman, 1975, p. 64. WiLDBRIDGE, Thomas T., The Hull Letters..., op. cit., p. 147, lettre de Peregrine Pelham du 26 mai 1646: "This day the Maior of Newcastle tould me that the French have taken divers shipps $w^{\text {th }}$ the King's Commission and throwne the men overbord. " DUQUESNE, Jacques, Jean Bart, Paris, Seuil, 1992, p. 15 : les marins français clouaient les Hollandais à fond de cale avant d'incendier leur navire; ces derniers jetaient par-dessus bord les marins espagnols ficelés par deux; STRADLING, Robert A., The Armada of Flanders. Spanish maritime Policy and European War, 1568-1668, Cambridge, Cambridge University Press, 2003, p. 212 : plainte contre le capitaine Pierre Maitens de Dunkerque pour avoir mis un jeune homme à la torture. OGILVIE, Bertrand, L'Homme jetable. Essai sur l'exterminisme et la violence extrême, Paris, éd. Amsterdam, 2012, p. 34 : les cargaisons des compagnies de commerce hollandaises passent avant les équipages d'après leur devise: «Navigare necesse est, vivere non necesse » ( Il est nécessaire de naviguer, il ne l'est pas de vivre »). ARMitaGE, David, The ideological Origins of the British empire, Cambridge, Cambridge University Press, 2009, p. 118-120. 
6. KEPLER, Jon S., The Exchange of Christendom. The international entrepôt at Dover, 1622-1641, Leicester, Leicester University Press, 1976, p. 115 : «our great trade depends upon the troubles of our neighbours [...] if a peace happen betwixt France, Spain, and the United Provinces, all these will share what we now possess alone ».

7. HASQUIN, Hervé, Louis XIV face à l'Europe du Nord, Bruxelles, Racines, 2005, p. 51. HILL, Christopher, The Century of Revolution, 1603-1714, New York, Norton \& Co, 1982, p. 124-136: il qualifie la période 1640-1660 de «turning point» pour le commerce anglais.

8. Cet article doit beaucoup à la fructueuse coopération heuristique entretenue avec Baptiste Étienne (universités de Rouen et de Caen) que je remercie très cordialement et des recherches duquel on attend beaucoup sur les Mazarinades en Normandie.

9. Rommelse, Gijs, «Y a-t-il eu une révolution navale au début de l'époque moderne? Les relations entre la raison économique d'État et la guerre maritime ", Revue d'Histoire maritime, $\mathrm{n}^{\circ} 14,2011$, p. 239-257. ASHER, Eugene L., The Resistance to the Maritime Classes. The Survival of Feudalism in the France of Colbert, Berkeley/Los Angeles, University of California Press, 1960, vol. 66, p. 3-5 : sur les perturbations portuaires liées à ces levées en masse de matelots. Archives municipales du Havre (désormais Arch. mun. du Havre), fds anc., AA 18 : ordre aux autorités municipales de Dieppe, Le Havre, Harfleur, Fécamp de lever les matelots nécessaires au sieur Dumé et autres pour les vaisseaux du roi armés à Toulon et Marseille, 27 janvier 1645.

10. Arch. dép. de Seine-Maritime, 200 BP 35 : enregistrements des 4 avril 1654, 27 août et 11 octobre 1655, 7 janvier 1656 .

11. Biraben, Jean-Noël et Bonneuil, Noël, « Population et économie en Pays de Caux aux $\mathrm{XVI}^{\mathrm{e}}$ et $\mathrm{XVII}{ }^{\mathrm{e}}$ siècles ", Population, 6, 1986, p. 942 et p. 950, graph. $\mathrm{n}^{\circ}$ 8. DESARTHE, Jérémy, Le Temps des Saisons. Climat, événements extrêmes et sociétés dans l'Ouest de la France (XVIXIX ${ }^{e}$ siècles), Paris, Hermann, 2013, p. 36-39.

12. BnF, Mélanges Colbert (dés. Mél. Colb.), ms $\mathrm{n}^{\circ} 128$ bis, fol. 761-762: lettre du $1^{\mathrm{er}}$ avril 1665 des officiers de l'amirauté de Touques à Colbert. Lettres, instructions et mémoires de Colbert..., CLÉMENT, Pierre (éd.), Paris, Imprimerie Impériale, 1863, t. 4, p. 120, Colbert à Le Blanc intendant de la généralité de Rouen, le 10 juillet 1676; BnF, Mél. Colb., ms $\mathrm{n}^{\circ}$ 143, fol. 242-250: ordonnances de l'intendant de Rouen Jacques Barin de la Gallissonnière et procès-verbaux suite à l'évasion de marins de la flotte; ibid., fol. 279-283 et 284: rapports de Dumé d'Aplemont, Gabaret et du lieutenant de l'amirauté du Havre Claude Mathé à Colbert sur la levée des matelots dans le ressort de ce siège d'amirauté.

13. LemARCHAND, Guy, «Troubles et révoltes populaires en France, $\mathrm{XVI}^{\mathrm{e}}$-XVII ${ }^{\mathrm{e}}$ siècles. Essai de mise au point ", Cahier des Annales de Normandie, 2000, vol. 30, n 1, Féodalisme, société et Révolution française: études d'histoire moderne, XVI ${ }^{e}$ XVIII ${ }^{e}$ siècles, p. 131-158; AUBERT, Gauthier, Révoltes et répressions dans la France moderne, Paris, Armand Colin, 2015, p. 39-56.

14. VICKERS, Daniel, "The Price of Fish: A Price index for Cod, 1505-1892 ", Acadiensis, 1996, vol. $25, \mathrm{n}^{\circ} 2$, p. 96 , fig. $\mathrm{n}^{\circ} 1$. Le prix de la morue atteint un apex en 1629 (indice 101) puis se stabilise pendant 40 ans sur un plateau des prix (indice moyen 85) avant de décroître ensuite. 
15. BRÉARD, Charles, Les Archives de la Ville de Honfleur, Paris, A. Picard, 1885, p. 113-114 : la levée à Honfleur de 20 officiers et de 80 matelots pour la Marine royale est également rejetée entre avril et juin 1655 .

16. Arch. dép. de Seine-Maritime, 216 BP 371, p. 55 ; Arch. mun. du Havre, BB 6 , 18 mars-5 juin 1655.

17. Arch. mun. du Havre, fds anc., BB 6 : des troncs sont disposés en ville et sur les quais pour recueillir les dons afin de soulager la misère des familles. Arch. dép. de SeineMaritime, 216 BP 371: les capitaines terreneuviers havrais sont contraints à partir du 20 décembre 1658 d'embarquer, de salarier ou de récompenser selon l'usage habituel et de nourrir, en fonction de l'importance de l'équipage, un ou deux jeunes orphelins de l'hôpital du Havre pour l'instruire gratuitement dans la navigation afin de servir plus tard dans les « armes navales ».

18. Hugon, Alain, "Existe-t-il une fronde normande?", dans BougY, Catherine et POIREY, Sophie (dir.), Images de la contestation du pouvoir dans le monde normand ( $x^{e}$-XVIII siècle), actes du colloque de Cerisy-la-Salle, 29 septembre-3 octobre 2004, Caen, Presses universitaires de Caen, 2007, p. 233-246.

19. Arch. mun. du Havre, fds anc., AA 26, Relation véritable de ce qui s'est passé à la prise de la ville de Harfleur près Le Havre..., Paris, chez Nicolas de la Vigne, 1649, 8 p. B RÉARD, Charles, Les Archives..., op. cit., p.60, n. 2. Sur la Fronde en Normandie: MÉTHIVIER, Hubert, La Fronde, Paris, PUF, 1984, p. 135. Logié, Paul, La Fronde en Normandie, Amiens, 1951-1952, s.l., vol. 2, La "guerre d'Harcourt ». GoujARD, Philippe, La Normandie aux XVI et XVII siècles face à l'Absolutisme, Rennes, Ouest-France Université, 2002, p. 220-227.

20. KNACHeL, Philip A., England and the Fronde. The Impact of the English Civil war and revolution on France, Ithaca, Cornell University Press, 1967, p.159-160. Arch. mun. du Havre, fds anc., BB 6 : le 19 avril 1652, les marchands havrais Broques et Grenier informent la duchesse d'Aiguillon, gouverneur du Havre, que 60 à 70 vaisseaux de guerre anglais s'équipent ou sont en mer, ce qui fait craindre une attaque du Havre. Ils lui demandent une avance de fonds pour l'achat de 10 mois de vivres et de munitions de guerre pour la défense de la ville et du port ainsi que le paiement des soldes pour la garde de la citadelle.

21. KNACHEL, Philip A., England..., op. cit., p. 251 : Hugh Morel à Paris à John Thurloe, secrétaire d'État, lettre du 27 mai 1655.

22. Arch. dép. de Seine-Maritime, 216 BP 371, p. 64 et 70 : les pêcheurs des côtes et des rivières navigables de Normandie arment sans prendre de congés annuels ou de permissions. CleIRAC, Estienne, Les Us et coutumes de la mer, divisés en trois parties, Amsterdam, 1788, p. 323 et 334.

23. Tallemant des RéAuX, Gédéon, Historiettes [1650], Paris, La Pléiade, 1960, vol.1, p. $304-311$.

24. Robillard de Beaurepaire, Charles de, "Cahiers des États de Normandie de février 1655 », Mélanges, Société d'Histoire de la Normandie, $1^{\text {re }}$ série, Rouen, A. Lestringant, 1891, p. 22. L'arrêt du Conseil du $1^{\mathrm{er}}$ mars 1663 interdit aux commandants, officiers ou soldats des places de Dieppe, du Havre, Honfleur, Pont-de-l'Arche, Andelys, ChâteauGaillard et Meulan d'exiger un droit sur les navires en Seine ou dans ces ports.

25. Robillard de Beaurepaire, Charles de, "Cahiers... », art. cité, p. 21. Dessert, Daniel, Fouquet, Paris, Fayard, 1987, p. 211 et 222 : ces ports sont localisés dans les 
gouvernements de La Rochelle, Aunis, Brouage, Oléron et Ré, acquis par Mazarin. Le vice-amiral de France François de Nuchèze est intendant de la Marine, de la navigation et commerce de France dans le Ponant depuis1651.

26. Cleirac, Estienne, Les Us..., op. cit., p. 217 et 313. Ibid., p. 324 : arrêt du 17 août 1658 interdisant aux capitaines français de posséder différents pavillons pour tromper l'ennemi en mer et en faire la prise.

27. JaCQUART, Jean, «Colbert », dans Méchoulan, Henry et CORNETTE, Joël (dir.), L'État Classique, 1652-1715, Paris, Vrin, 1996, p. 189-190 ; MeYER, Jean, Colbert, Paris, Hachette, 1981, p. 54 ; BLANQUIE, Christophe, « Fiscalité et vénalité des offices présidiaux », Histoire, économie \& société, $2004,23^{\mathrm{e}}$ année, $\mathrm{n}^{\circ} 4, \mathrm{p}$. 481-482 : les prix des offices atteignent leur maximum avant une lente décrue séculaire. Devant "l'horrible multiplicité des officiers", Colbert souhaite la suppression de tous les offices dans son mémoire du 6 août 1664.

28. Arch. dép. de Seine-Maritime, 216 BP 371, ordonnance du 26 février 1658. Ibid., l'Amirauté de France ordonne le 23 août 1658 aux officiers du siège du Havre de saisir la frégate du nommé Collard, armée sous la commission du roi de Portugal, ainsi que les prises hollandaises faites par ce navire et mouillées en rade du Havre. LE B OUËDEC, Gérard, «L'État et le cabotage en France et en Europe aux XVII ${ }^{\mathrm{e}}$-XVIII ${ }^{\mathrm{e}}$ siècles » dans : LE BOUËDEC, Gérard et CHAPPÉ, François (dir.), Pouvoirs et littoraux du XVe au XXe siècle, actes du colloque international de Lorient, 24-26 septembre 1998, Rennes, PUR, 2000, p. 388-389.

29. Arch. dép. de Seine-Maritime, 216 BP 371 : extrait des registres du conseil d'État du 27 janvier 1657 : le Conseil impose aux armateurs de ne prendre que les congés et passeports de l'amiral, avec l'obligation de ne pas sortir d'un port et de ne pas naviguer en Manche orientale sans être placé sous la surveillance de deux frégates d'escorte de la Marine aux mêmes frais que ceux exigés les années précédentes par les capitaines d'escorte.

30. Arch. dép. de Seine-Maritime, 216 BP 371, p. $72: 1^{\text {re }}$ contravention : amende montant au quart de la valeur du vaisseau et de la cargaison ; $2^{\mathrm{e}}$ fois : confiscation des marchandises et saisie des biens et effets des marchands " habituéz » en France qui auraient chargé en fraude sur des vaisseaux étrangers sans permission.

31. Arch. dép. de Seine-Maritime, 216 BP 371 : enregistrement de l'ordonnance du duc de Vendôme le 17 octobre 1656 au greffe de l'amirauté du Havre.

32. Arch. mun. du Havre, fds anc., BB 6 : Papillon, échevin du Havre, a été reçu par la duchesse, qui tient le gouvernement du Havre, en présence de Denis Marin (traitant, intendant des finances et secrétaire particulier de Colbert en 1661) et de Gargan, intendant de finances. La députation havraise repart bredouille : rien n'est alloué au rétablissement du bassin, du pont et des barres de chasses du port, 3 mars 1653.

33. BRÉARD, Charles, Les Archives..., op. cit., p. 117 : constatation échevinale du 17 février 1661 des ruines survenues aux quais, havres, jetées et murailles d'Honfleur depuis la guerre dernière. Depuis 1651 la rivière de l'Orne à Caen est impraticable pour les barques et bateaux le long des murailles de la ville.

34. GoUHIER, Pierre, «La Normandie, province frontière! », Annales de Normandie, 1965, $\mathrm{n}^{\circ} 1$, p. 129-133.

35. DAEFFLeR, Michel, «Les frégates gardes-côtes au XVII ${ }^{e}$ siècle : la mise en place de la protection des côtes sous Richelieu », dans RIDEL, Élisabeth, LENHOF, Jean-Louis et 
Boutin, Christophe (dir.), Le Littoral: contrôle, surveillance et usages des côtes, communication présentée au séminaire annuel du Pôle maritime de l'université de Caen, 20 décembre 2012, Caen (MRSH). [http://www.unicaen.fr/recherche/mrsh/ forge/6437].

36. BIENASSIS, Loïc, «Richelieu and Britain (1634-1642) ", dans RICHARDSON, Glen (dir.), The Contending Kingdoms'. France and England, 1420-1700, Londres, Ashgate, 2008, p. 133-145. SuE, Eugène, Correspondance de Henri d'Escoubleau de Sourdis, Paris, Crapelet imp., 1839, t. 3, p. 201.

37. J AMES, Alan, «Voyage et Inspection Maritime de M. d'Infreville sur les Côtes Françaises de l'Océan, 1631 ", French History, vol. 15, n 4, 2001, p. 448-490. Coluins, James B., "La flotte normande au commencement du XVII e siècle: Le Mémoire de Nicolas Langlois (1627) », Annales de Normandie, 1984, vol. 34, p. 367.

38. CORVISIER, André, La France de Louis XIV. Ordre intérieur et place en Europe, Paris, Sedes, 1994, p. 145. BRÉARD, Charles, Les Archives..., op. cit., p. 302 : Honfleur arme 217 navires pour Terre-Neuve et le Canada, 6 pour les Antilles, 4 pour les Indes orientales et 7 en course (total : 22000 tonneaux) entre 1636 et 1645. CARPIN, Gervais, Le Réseau du Canada. Étude du mode migratoire de la France vers la Nouvelle-France (1628-1662), Sillery-Paris, Septentrion et Presses de l'université de Paris-Sorbonne, 2014, p. 33, tabl. $\mathrm{n}^{\circ} 1$ et p. 34, tabl. $\mathrm{n}^{\circ} 2$ : les expéditions d'émigrants depuis Dieppe cessent totalement après 1634 pour la région du golfe du Saint-Laurent et sont totalement suspendues de 1645 à 1652 à destination de la vallée du Saint-Laurent. JAMES, Alan, Navy and Government in Early Modern France 1572-1661, Woodbridge, The Boydell Press, 2004, p. $158:$ : French merchants enjoyed very little protection from this navy, remaining prey to rampant privateering on both seas ".

39. M eYER, Jean, Béveziers (1690). La France prend la maitrise de la Manche, Paris, Economica, 1993, p. 25-26.

40. Morieux, Renaud, Une mer pour deux royaumes. La Manche, frontière franco-anglaise (XVII ${ }^{e}$-XVIII ${ }^{e}$ siècles), Rennes, PUR, 2008, p.70, graph. 1 et p. 76: le nombre de cartes représentant la Manche augmente pendant les années 1640-1650. Le toponyme Manche commence à être employé dans les textes français entre 1623 et 1656 avant de s'imposerentre 1670 et 1690 .

41. Arch. mun. du Havre, fds anc., BB 6 : des marchands havrais dénoncent l'armement en guerre dans leur port d'un brigantin qui a déjà pris ou pillé plusieurs navires dont les marchandises leur étaient destinées, sous le prétexte que le pavillon et la marchandise étaient anglais, 11 septembre 1653. JAL, Augustin, Nouveau Glossaire Nautique, Paris CNRS éditions, 2011, t. NOP, p. 1594 : sur la définition de la piraterie ; ibid., Paris, 1978, t. c, p. 363 : sur la définition de la course.

42. BATTESTI, Michèle, «La piraterie maritime : réflexions géostratégiques », Diplomatie, $\mathrm{n}^{\circ}$ 56, 2012, p. 59.

43. Arch. dép. de Seine-Maritime, 216 BP 371, arrêt du Conseil du 11 juillet 1657 : interdiction signifiée aux capitaines corsaires de Montchel et Delavigne d'appareiller du Havre sur leurs frégates le Protecteur et le Sainct Pierre en raison de leur artillerie insuffisante ( 6 canons et 12 mousquets pour chaque frégate) à moins d'armer une troisième frégate. 
44. Arch. mun. du Havre, fds anc., BB 5 : dès 1649, les armateurs havrais doivent acquitter un droit de 100 livres par navire pour les frais d'armement des frégates d'escorte des convois de navires terre-neuviers, délibération échevinale du 2 juillet 1650.

45. Lettres..., op. cit., CLÉMENT, Pierre (éd.), t. I, p. 489. MURAT, Inès, Colbert, Paris, Fayard, 1980, p. 44 : Colbert et Mazarin spéculent en 1654 sur les prises maritimes pour financer la guerre contre l'Espagne.

46. CAVERT, William M., The Smoke of London. Energy and Environment in the Early Modern City, Cambridge, Cambridge University Press, 2016, p. 160.

47. Willan, Thomas S., The English Coasting Trade 1600-1750, Manchester, Manchester University Press, 1938, p. 26-28.

48. Sмiтh, Raymond, Sea-Coal for London. History of the coal factors in the London market, London, Longmans, 1961, p. 17.

49. Hope, Ronald, A new history of British shipping, Londres, John Murray, 1990, p. 191 ; VILLIERS, Patrick, « Le rôle de la course et de la contre-course dans le développement et le déclin des puissances maritimes européennes (1560-1815) », dans BuchET, Christian, MEYER, Jean et Poussou, Jean-Pierre (dir.), La Puissance maritime, actes du colloque international de l'Institut catholique de Paris, 13-15 décembre 2001, PUPS, 2004, p. 451-452. StRadling, Robert A., The Armada of Flanders. Spanish Maritime Policy and European War, 1568-1668, Cambridge, Cambridge University Press, 2003, p. 219-220 et 256, appendix 11. CAPP, Bernard, Cromwell's Navy. The Fleet and the English Revolution, 1648-1660, Oxford, Clarendon Press, 2001, p. 103. V ILLIERS, Patrick, Les Corsaires du Littoral. Dunkerque, Calais, Boulogne, de Philippe II à Louis XIV (1568-1713), Villeneuve d'Ascq, Presses universitaires du Septentrion, 2000, p. 147-148.

50. CAPP, Bernard, Cromwell's Navy..., op. cit., p. 104 ; A collection of the State papers of John Thurloe, esq., Birch, Thomas (éd.), London, Thomas Woodward, 1742, vol.6, p. 131. BARRAT, John, Cromwell's Wars at Sea, Barnsley, Pen \& Sword books, 2006, p. 178.

51. S TRADLING, Robert A., The Armada..., op.cit., p. 204-228. CAPP, Bernard, Cromwell's Navy..., op. cit., p. 73-106.

52. Poussou, Jean-Pierre, Les Îles Britanniques, les Provinces-Unies, la Guerre et la Paix au XVII siècle, Paris, Économica, 1991, p. 73-76: pour les relations franco-anglaises au milieu des années 1650 ; CoWARD, Barry, The Cromwellian Protectorate, Manchester/New York, Manchester University Press, 2002, p. 135-136.

53. C APP, Bernard, Cromwell's Navy..., op.cit., p.70: Jacob Reynolds, marchand commissionnaire anglais établi à Saint-Malo et partisan des Parlementaires, est emprisonné au début de 1650 ; son comptoir est ruiné.

54. B ARRAT, John, Cromwell's Wars..., op. cit., p. 66-89 et 179: l'amiral Blake s'empare successivement en 1651 des bases corsaires royalistes des Sorlingues (îles Scilly), la « seconde Alger ", puis des îles Anglo-normandes.

55. K NACHEL, Philip A., England..., op. cit., p. 112-275. Arch. dép. de Seine-Maritime, 2E1/2396, acte du 12 octobre 1651: Jacques Botteler (Buttler), vice-roy d'Irlande, marquis d'Ormonde, nomme son procureur Moragh O'Bryen, baron d'Inchinquin, pour les prises à venir de la frégate la Dilligente de 50 tx dans laquelle ils sont intéressés. 
56. AsHLEy, Maurice, Financial and commercial policy under the Cromwellian Protectorate, Londres, Frank Cass \& Co, 1962, p. 156 : acte du 31 octobre 1651 attribuant $15 \%$ des recettes à venir sur les douanes pour provisionner les frais de convois. Arch. dép. de Seine-Maritime, 204 BP 5 : requête de Jehan Stmerisson maître de navire anglais pour la délivrance de son navire à Dieppe en 1650 ; affaire des marchands anglais Jones Caddenaladdix et Anthoine Brones en 1651 à Rouen.

57. Wilson, Charles, Profit and Power. A Study of England and the Dutch Wars, Den HaagBoston-London, Martinus Nijhoff, 1978, p. 58.

58. A NDERSON, Roger C., "Blake's capture of the French fleet before Calais on 4 September 1652 ", Mariner's Mirror, t. 48, 1962, p. 192-207. Powell, J. R., Robert Blake General-at-Sea, London, Collins, 1972, p. 165-168.

59. KorR, Charles P., Cromwell and the New Model Foreign Policy, Berkeley/Los AngelesLondon, University of California Press, 1975, p. 44-157.

60. BnF, ms fr. 18592, Mémoire pour les marchands de Paris, Rouen, St. Malo, Nantes, Morlaiz, Le Havre \& Dieppe, trafiquans en mer (1653). L'auteur du mémoire réclame de l'État la reprise du commerce franco-anglais, mais préconise de ne pas restituer les marchandises anglaises confisquées, de saisir les navires anglais dans les ports français et de délivrer des lettres de marque pour compenser les pertes infligées par les Anglais. PERNOT, Michel, La Fronde 1648-1653, Paris, Éditions de Fallois, 1994, p. 335 : les Huguenots modérés de l'Ormée repartent bredouilles de leur ambassade à Londres en avril 1653.

61. BRÉARD, Charles, Les Archives..., op. cit., p. 110-112 : une contribution de 40 livres par maitre de navire ainsi qu'une levée au marc la livre sur les intéressés sont levées à Honfleur pour financer à Londres la délivrance des bâtiments capturés et les réparations des pertes subies par les armements. Arch. mun. du Havre, fds anc., BB 6 : l'année suivante, 20 terre-neuviers havrais sont pris « ces jours passés » par les Anglais, 8 août 1654.

62. CAPP, Bernard, Cromwell's Navy..., op. cit., p. 92 et LESPAGNOL, André, « Les îles anglonormandes et la France de l'Ouest: une relation particulière » dans: CHAUvaUD, Frédéric et PÉRET, Jacques (dir.), Terres Marines. Études en hommage à Dominique Guillemet, Rennes, PUR, 2006, p. 85-90 : trois frégates anglaises causent en avril 1654 des pertes très élevées dans une flotte de 40 terre-neuviers malouins provoquant de violentes émeutes anti-anglaises dans ce port. Lettres du cardinal Mazarin pendant son ministère, CHÉRUEL, Adolphe (éd.), Paris, Imprimerie nationale, 1890, t. 6, p. 157 : Mazarin s'en plaint au baron de Baas dans sa lettre du 8 mai 1654 : «Les sujets du Roy, sur la foy de la bonne reception que l'on a faicte à $\mathrm{M}$. L'Ambassadeur et à vous à Londres, sont tous les jours pris à la mer, pillez et ruinez par les Anglois [...] Il ne faut pas oublier aussy de se plaindre hautement de ce qui a esté faict aux vaisseaux de Saint-Malo ». Ibid., p. 170 : lettre de Mazarin à de Bordeaux à Londres du 24 mai 1654 : « Nous venons d'avoir advis que dix-huit vaisseaux anglois, s'estant approchez des costes de Normandie, avoient mis des gens à terre en un lieu appelé Cancale, pour ravager le pays. [...] en un instant il est accouru plus de cinq mille hommes armez, qui ont obligé ces gens-là de s'en retourner plus viste qu'ils n'estoient venus ».

63. JONES, James R., The Anglo-Dutch Wars of the seventeenth Century, London, Longman, 1996, p. 143.

64. B RÉARD, Charles, Les Archives..., op.cit., p. 61 et p.112-113: lettre de cachet du 25 janvier 1654 aux maîtres de navire honfleurais. 
65. ASHLEY, Maurice, Financial..., op. cit., p. 138-139 et 184. LIPSON, Ephraim, The Economic History of England, London, A \& C. Black, 1931, vol. 3, p. 99-100.

66. RoutLEDGE, Frederick J., England and the Treaty of the Pyrenees, Liverpool, Liverpool University Press, 1953, p. 3-5. Arch. dép. de Seine-Maritime, 216 BP 371 : ordonnance du duc de Vendôme du1 ${ }^{\mathrm{er}}$ février 1656.

67. Robillard de Beaurepaire, Charles de, « Cahiers... », art. cité, p. 21-22.

68. Correspondance administrative sous le règne de Louis XIV, DEPPING, Georg Bernhard (éd.), Paris, Imprimerie Impériale, 1854, t. 3, p. 504, Colbert à de Souzy, intendant de Lille, le 24 janvier 1670.

69. VoYSIN DE LA NOIRAYE, Jean-Baptiste, Mémoire sur la Généralité de Rouen (1665), ESMONIN, Edmond (éd.), Paris, Hachette, 1913, p. 193 ; sur Fécamp : ibid., p. 195. BnF, Mél. Colb., ms 128 bis, rapport du $1^{\mathrm{er}}$ mai 1665 de Rigoult, procureur de l'amirauté de Saint-Valéry-enCaux, sur le « peu de vaisseaux qui y seroient entrés pendant la guerre et la perte que les habitants dudict Saint Vallery ont faict de près de quatre-vingt navires tant terreneufviers que marchands ny en ayant a present dans ledict bourg que six a sept petits... "; Correspondance administrative..., op.cit., t. 3, p. 335 : lettre des échevins de Dieppe à Colbert du 18 mai 1663 : «Et nous pouvons dire que les déprédations qui ont esté ci-devant faictes par les ennemis de la couronne pendant la guerre ont fait cesser en ce port la navigation et le commerce... »

70. Service historique de la Défense, Vincennes, Service hydrographique, SH 48, Enquête des amirautés de 1665, procès-verbal de l'amirauté d'Eu-Le Tréport adressé à Colbert.

71. BRÉARD, Charles, Les Archives..., op. cit., p. 108-110. Arch. dép. de Seine-Maritime, 204 BP 5 : états et déclarations pour le droit de garde de 7 livres par lest de harengs pour les frais des trois vaisseaux qui ont gardé et conservé la pêcherie la saison précédente (1651-1652).

72. Célérité, nécessité et avidité.

73. JAL, Augustin, Nouveau..., op. cit., t. H, p. 902 : le heu est un bâtiment "grossier et massif ", à fond plat, utilisé pour le trafic maritime en mer du Nord et en Manche.

74. Arch. mun. du Havre, fds anc., BB 6 : le capitaine havrais Jean Raisin, muni de son congé, appareille pour le Canada sans déclarer les marchandises embarquées, 2 janvier 1655. Arch. dép. de Seine-Maritime, 216 BP 122 : 3 navires entrés au Havre en 1655 et 1656 ne sont pas relevés en sorties dans le registre 200 BP 35, probablement parce qu'ils ont été vendus avec leur cargaison dans ce port. Aux 173 actes, s'ajoutent 5 déclarations faites au titre de la levée d'hommes d'équipage pour le service du roi sur les navires marchands français.

75. Arch. mun. du Havre, fds anc., BB $6: 24$ navires, probablement des terre-neuviers d'après les noms des capitaines évoqués, 2 janvier 1655.

76. Par exemple pour l'année complète 1655 , on dénombre 52 soumissions au Havre contre 353 congés délivrés à Caen. Un article est en préparation à partir de l'analyse des congés de l'amirauté de Caen pour mesurer la reprise maritime dans ce port à la fin de la décennie 1650 .

77. Michon, Bernard, «Les marchands de Nantes et le commerce avec Bilbao au milieu $\mathrm{du} \mathrm{XVII}^{\mathrm{e}}$ siècle " dans SAUPIN, Guy et al., Le commerce franco-atlantique franco-espagnol. Acteurs, négoces et ports (XV'-XVIII siècle), Rennes, PUR, 2008, p. 255 : la similarité entre la 
répartition chronologique des affrètements passés à Nantes et Le Havre pendant les années 1654-1655 est frappante.

78. GRAHAM, Éric J., A maritime History of Scotland, 1650-1790, Edinburgh, Birlinn, 2015, p. 13 : la flotte marchande écossaise est estimée en 1656 à un total variant entre 139 et 143 bâtiments pour un tonnage oscillant entre 5776 et 6306 tonneaux, soit une moyenne de 41 à 44 tonneaux par navire, ce qui sous-entend que la flotte marchande écossaise est surtout orientée vers le cabotage et la pêche.

79. Graham, Éric J., Ibid., p. 136 et suiv.: les troupes parlementaires prennent puis occupent les ports de la Clyde qui subissent des dégâts très importants. Dundee est mis à sac et «almost all the ships and vessels of his Majesty'subjects of Scotland were during the last usurpation [le gouvernement de Cromwell]: taken, burnt or destroyed». Le trafic maritime s'effondre à Ayr ou Kirkcaldy. Le trafic de Leith chute des deux tiers entre 1638 et 1660. En revanche, d'autres ports non occupés comme Aberdeen ou Dumbarton semblent avoir conservé une bonne partie de leurs trafics, leur commerce ayant même prospéré pendant l'interrègne.

80. Poulsen, Bo, Dutch Herring. An environmental history, c. 1600-1860, Amsterdam, Aksant, 2008, p. 54-55; Smout, T. Christopher, Scottish Trade on the Eve of Union 1660-1707, Edinburgh/London, Oliver \& Boyd, 1963, p. 222. Rich, Edwin E. et WiLson, Charles H., The Cambridge Economic History of Europe, Cambridge, Cambridge University Press, 1977, vol. 5, p. 147-154.

81. GibSon, Alex et Smout, T. Christopher, Prices, food and wages in Scotland 1550-1780, Cambridge, Cambridge University Press, 1995, p. 273 et suiv.

82. D AVIDSon, James D.G., Scots and the Sea. A Nation's Lifeblood, Edinburgh/London, Mainstream publishing, 2005, p. 318-327 : liste des ports, havres, terminaux de ferries et chantiers navals écossais à l'époque moderne. Smout, T.C., Scottish Trade..., op. cit., p. 299 et suiv., cartes détaillées des ports écossais.

83. HinToN, R.W.K. (dir.), The Port Books of Boston 1601-1640, Hereford, Lincoln Record Society, vol. 50, 1956, p. 329 et suiv. : les sorties du Havre vers Boston sont récentes car les seuls ports français ayant des relations maritimes avec Boston avant 1640 sont Bordeaux, Calais, La Rochelle et Saint-Malo.

84. Hope, Ronald, A new history..., op. cit., p. 194 : sur les transformations rapides des bâtiments anglais de moins de 50 tonneaux au milieu des années 1650. PoPE, Peter E., Fish into Wine. The Newfoundland Plantation in the Seventeenth Century, Chapel Hill-London, University of North Carolina Press, 2004, p. 146-147 : la plupart de ces ports arment pour Terre-Neuve et le «sack trade».

85. Blamont, Jacques, Le Lion et le Moucheron. Histoire des Marranes de Toulouse, Paris, Odile Jacob, 2000, p. 60.

86. Arch. dép. de Seine-Maritime, 216 BP 122 : sentence de l'amirauté du Havre du 8 mai 1657 entre Jean Le Gouvant, maitre de navire de Landerneau, accompagné de Nicolas Le Tournois son interprète-conducteur et de Louys Lyon son avocat et Longuemare, marchand de Rouen associé à plusieurs marchands fruitiers du Havre. BotTin, Jacques, «La mer comme vecteur des échanges » dans : CABANTous, Alain, LeSPAGnol, André et Pé RON, Françoise (dir.), Les Français, la Terre et la Mer XIII $-\mathrm{XX}^{e}$ siècle, Paris, Fayard, 2005, p. 251 : la présence dans la seconde moitié du $\mathrm{XvI}^{\mathrm{e}}$ siècle en vallée de Seine et jusqu’à 
Paris de nombreux petits bateaux de 40 tonneaux au plus chargés d'agrumes atteste du développement des échanges avec le Portugal.

87. Arch. dép. de Seine-Maritime, 216 BP 371 : Benjamin Duval, le commissaire de la Marine au Havre, commissionné par Louis Virvoudet, sieur de Brye, receveur du domaine royal de Lyons (Lyons-la-Forêt) en 1656, des droits de l'amiral en Normandie pour la recette des droits de l'amirauté au Havre le 27 novembre 1659, se déclare marchand au Havre et chargé d'affaires, par sa procuration du 6 avril 1660 passée à Rouen chez Borel et Cavé, notaires de la Vicomté, en faveur de François Van Emericq, marchand de Rouen et armateur du Salvator Mundy de 300 tonneaux, chargé de ses marchandises à Amsterdam et prêt à partir pour la Baltique sous le commandement de Louis de Neufville, capitaine du Havre. Oxford University, Bodleian Library, Special collection, ms. carte 222, fol. $\mathrm{n}^{\circ}$ 426-427, avis de Paris envoyés au duc d'Ormonde du 20 juin 1663 : Benjamin Duval, marchand au Havre, est mis en état d'arrestation en tant qu'agent de Fouquet et pour ses implications dans plusieurs actes de piraterie maritime commis en haute mer.

88. GAUTIER, Bertrand, «Les négociants étrangers à Rouen à l'époque de Richelieu et de Mazarin (1625-1660) », Annales de Normandie, no 3, 2005, p. 252.

89. BotTin, Jacques, « La mer... », art. cité, p. 185-190 : pour une vue comparative sur les échanges maritimes interrégionaux en Europe.

90. RösSNER, Philipp R., «Small is beautiful ? Dutch economic prominence and Scottish economic development in the "Long Seventeenth Century", 1600-1750: fisheries and the foreign trades ", dans Denzel, Markus A., De VRIES, Jan et Rössner, Philipp R. (dir.), Small is beautiful? Interlopers and smaller trading Nations in the Pre-industrial period, Proceedings of the $\mathrm{xv}^{\text {th }}$ World economic History congress, Utrecht, 2009, Stuttgart, Franck Steiner Verlag, 2011, p. 136 : «Scots ships on the other hand were small on average. Partly this was a result of the fact that most of Scotland's trade between 1600 and 1730 was with England, Ireland or continental Europe. "

91. De BRUYN Kops, Henriette, A Spirited Exchange. The Wine and Brandy Trade between France and the Dutch Republic in its Atlantic Framework, 1600-1650, Leiden-Boston, Brill, 2007, p. 188 : Rouen est une étape majeure dans le transport des vins entre Hambourg, Nantes et Bordeaux pour les beurtvaart (rouliers) hollandais affrétés pour le réseau marrane mais l'escale havraise des navires hambourgeois se limite au seul navire du capitaine Girard Herman Bosher chargé de 60000 cercles de futailles et de 1500 douzaines de bouteilles de verre pour Bordeaux (Jacques Chapelle, courtierinterprète au Havre), acte du $1^{\text {er }}$ septembre 1654 .

92. Une base comparative approchante mais à employer avec réserve: Arch. dép. de Seine-Maritime, 216 BP 127 bis: congés distribués au Havre en 1670, année de comparaison la plus proche : cabotage provincial (1952 tx pour 60 bâtiments); cabotage interprovincial (12 349 tx pour 93 navires); cabotage européen ( 954 tx pour 10 navires), soit sur la base de l'année 1654 un repli de plus de $50 \%$ des sorties au moins.

93. Arch. mun. du Havre, fds anc., BB 6 : l'échevinage havrais considère que le projet fiscal d'un nouveau droit de salines «ruinerait l'unique commerce [terre-neuvier] qui reste à la ville... », 18 avril 1654 .

94. Coluins, James B., « La flotte... », art. cité, p. 380, tabl. V. 
95. RichARD, Robert et VATinel, Denis, «Le consistoire de l'église réformée du Havre au XVII ${ }^{\mathrm{e}}$ siècle : les laïcs (Étude sociale) ", Bulletin de la Société de l'Histoire du Protestantisme Français, vol. 128 (juillet-août-septembre 1982), p. 283-362.

96. ÉTIENNE, Robert (dir.), Histoire de Bordeaux, Toulouse, Privat, 2001, p. 151-162. BotTIN, Jacques et LESPAGNOL, André, « Un couple improbable entre concurrence et coopération : Rouen et Saint-Malo aux Temps modernes » dans BRIAN, Isabelle (dir.), Le Lieu et le Moment. Mélanges en l'honneur d'Alain Cabantous, Paris, Publications de la Sorbonne, 2015, p. 31-57.

97. Frondeville, Henri et Odette de, Les conseillers du Parlement de Normandie de 1641 à 171. Recueil généalogique établi sur la base du Manuscrit Bigot de la Bibliothèque de Rouen, vol. 4, Rouen, Lestringant, 1970, p. 292 : Robert Bigot (1633-1692), baron de Montville, avocat puis conseiller au parlement de Rouen en 1654, conseiller au parlement de Paris.

98. Bib. mun. de Rouen, Montbret 986, Depuis la S[ain]t Martin 1657 Jusques a la S[ain]t Martin 1658, fol. 7-8: Robert Bigot recopie un «Mémoire pour le Commerce contre le pretendu Establissement de deux greffiers ou Nottaires dasseurance », dont est extraite cette citation signalée par Baptiste Etienne que je remercie.

99. CleIRAC, Estienne, Les Us..., op. cit., p. 315 : les marchands et les capitaines français fournissent l'ennemi espagnol en munitions navales, acte du 4 mars 1653.

100. Correspondance administrative..., op. cit., t. 3, p. 337, Clerville à Colbert du 18 mai 1663 à Rouen : « [l'alarme de la course anglaise] oblige les négocians à retourner à leur vieille et meschante coutume, c'est-à-dire à refretter des vaisseaux hollandois pour faire porter leurs marchandises par les costes de la mer Océane avec plus de seureté ». Arch. mun. du Havre, fds anc., BB 6 : fin mars 1655, trois maitres de navire du Havre affrètent trois bâtiments hollandais pour effectuer leur campagne à Terre-Neuve et ne pas être saisis par les Anglais. Ibid., interdiction donnée aux habitants du Havre de prêter leur nom à des marchands forains ou étrangers pour armer à Terre-Neuve, $1^{\text {er }}$ décembre 1657.

101. A collection of the State papers of John Thurloe, esq., BIRCH, Thomas (éd.), London, Thomas Woodward, 1742, vol. 7, p. 581, lettre reçue du Lord Chief justice Saint John du 28 décembre $1658:$ « He [M. Foxcrofte], tells me, that almost all the merchants begin to trade in Dutch bottoms. The consequence, you know, will be noe lesse, then that in a shorte time we shall have noe ships of our owne; and of the transportation of wools. ".

102. Bib. nat., Cinq cents de Colbert 203, Memoire Pour les Marchands de Paris, Roüen, S. Malo, Nantes, Morlaiz, Le Havre, \& Dieppe, Trafiquans en Mer, p. 3.

103. Robillard de Beaurepaire, Charles de, «Cahiers... », art. cité, p. 19.

104. MicHon, Bernard, « Les marchands... », art. cité, p. 263.

105. L ougH, John, France observed in the Seventeenth Century by British Travellers, Stockfield, Oriel Press, 1985, p. 18. COXERE, Edward, Adventures by sea, MEYERSTEIN, E.H.W. (éd.), London, Oxford University Press, 1946, p.3: le jeune Edward Coxere, âgé de quatorze ans en 1647, traverse la Manche pour apprendre le français au Havre de Grâce pendant onze mois chez la veuve d'un brasseur local.

106. BASTIDE, Charles, The Anglo-French Entente in the seventeenth century, Londres, John Lane, 1914, p. 161-162 : l'éditeur imprimeur londonien William Du Gard (1606-1662) fait paraître en français son journal Les nouvelles ordinaires de Londres, de 1650 à 1658, lu par les marchands de la City afin d'être informés des mouvements de navires pirates, des 
armements ou des découvertes d'expéditions de marchandises anglais entreprises sous pavillon neutre.

107. Arch. dép. de Seine-Maritime, 4 E 3395, registre du temple protestant de Quevilly (1643-1659), registre des sépultures, acte du 15 décembre 1651.

108. PAIGE, John, The Letters of John Paige, London merchant, 1648-1658, STECKLEY, George F. (éd.), London, London Record Society, 1984, p. 7 et 43 : le marché nantais est pourtant plus profitable que celui de Rouen lors de la guerre maritime : "If you send a ship for France, let her go to Mr John Holle [at Nantes], which is a far better market than Rouen. ", lettre du 8 mai 1651 à William Clarke.

109. Morineau, Michel, "La Marine française de commerce de Colbert à Seignelay ", dans Méchoulan, Henry et CoRnetTe, Joël (dir.), L'État Classique..., op. cit., p. 243 et 247, n. 1. BARBour, Violet, "Dutch and English merchant shipping in the seventeenth century » dans CARUS-WILSON, E. M. (dir.), Essays in Economic History, London, Edward Arnold, 1954, vol. I, p. 249 : le taux de fret hollandais est bien moins cher (entre un tiers et la moitié) que ses concurrents anglais, écossais ou français au milieu du XvII ${ }^{\mathrm{e}}$ siècle, même en temps de paix. Ibid., p. 252, n.118: Houblon frères de Londres, futurs directeurs de la Banque d'Angleterre, procurent des passeports anglais aux navires hollandais durant la guerre de Hollande. Hope, Ronald, A new history..., op. cit., p. 190 : la construction d'une flûte coûtant 1300 livres sterling en Angleterre ne revient qu'à 800 livres sterling en Hollande en 1666. GAUTIER, Bertrand, « Les négociants... », art. cité, p. 247-266.

110. Oxford University, Bodleain Library, Special Collections, ms. carte 34 , fol. $n^{\circ} 622$, le comte de Saint Alban à Whitehall au duc d'Ormonde "recommends to the favour of the Lord Lieutenant the suit for removal of the restraint lately put, in Ireland, upon certain French ships belonging to Mr Wilkins, of Rouen, an English merchant", mars 1666.

111. Arch. dép. de Seine-Maritime, $2 \mathrm{E} 1 / 2705$, acte du 4 juin 1651 : le fret fixé à 132 livres le cent de baril de charbon, Oursel s'oblige à hypothéquer ses biens et son navire avec son " atellage ", Wilkings hypothèque le chargement; Adrian Oosterlingh et Nicolas Le Ricollais de Rouen, témoins. Suite à de mauvaises affaires, Wilkings, pourtant naturalisé français, repart vers 1665 s'établir en Angleterre après une séparation d'habitation et de biens d'avec sa femme restée à Rouen. Colvin, Howard, $A$ Biographical Dictionary of British Architects, 1600-1840, New Haven-London, Yale University Press, 1995, p. 172-176 : sur William Bruce, marchand à Rotterdam, correspondant entre Charles II en exil et le général Monck.

112. JAL, Augustin, Nouveau Glossaire Nautique, t.QRS, Paris, CNRS éditions, 2015, p. 1815 : la recousse est la reprise d'un vaisseau et de ses effets capturés en mer par les corsaires ; on les rend à l'armateur contre le tiers de leur valeur comme droit de recousse si la prise a été recapturée dans un délai de 24 heures après la première prise.

113. Arch. dép. de Seine-Maritime, $2 \mathrm{E} 1 / 2397$, acte du 15 mai 1652 . BnF, ms fr 16564 , fol. 528-533 : factum sur l'appel d'un jugement du conseil de Marine du 31 août 1645. Les marchands Jean Jouan, Anthoine Fauveau, Jacques Plansson et consorts de Paris et Rouen requièrent contre Jacques Loyseau, capitaine de la frégate la Marie Royale de Calais et les matelots, soldats, avitailleurs, bourgeois et armateurs du bâtiment corsaire que leurs barques et marchandises leur soient rendues «si elles se peuvent recouvrer en paiant par eux, suivant leurs offres les fraiz, salaires \& recompense de la recousse, conduite \& garde desdites barques \& marchandises... ». 
114. T homson, Janice E., Mercenaries, Pirates, \& Sovereigns, Princeton, Princeton University Press, 1994, p. 21-42: sur les conditions et méthodes de mise en place du mercenariat maritime à l'époque moderne.

115. COATES, Ben, The Impact..., op. cit., p. 90-108 et p. 163-199.

116. ABAD, Reynald, Le Grand Marché, Paris, Fayard, 2002, p. 805-811 et fig. $\mathrm{n}^{\circ} 30$ et 31 .

117. Arch. mun. du Havre, fds anc., BB 2 : liste des marins havrais détenus en pays barbaresque, notamment à Alger et Thunis (sic) et libération à 200 livres par tête, 13 janvier 1628.

118. Arch. mun. du Havre, fds anc., BB 5 : les avitailleurs havrais (Jean Simon dit Haultpierre, Pierre Barbé, Adrien Vénestal, Pierre Hantier, Henry Le Tailloys, Germain Lebaillif, Jouassin Crabin, Pierre Boucherot et Nicolas Le Rondel) des frégates de protection terre-neuvières armées en 1649 demandent une avance sur paiement pour leurs fournitures non encore réglées au 2 juillet 1650. L'échevinage ordonne aux deux « fermiers» (affréteurs armateurs) des frégates, Jacques Fontaine et Jacques Le Prêtre, de produire le rôle des maîtres de navires terre-neuviers qui ont bénéficié de cette protection à Terre-Neuve pour que ces derniers s'acquittent du paiement des fournitures à raison de 100 livres par navire, 2, 16 et 23 juillet 1650. BRÉARD, Charles, Les Archives..., op. cit., p. 106: assemblée des échevins honfleurais du 15 juillet 1649 délibérant sur la lettre des échevins du Havre invitant les marchands et armateurs de Honfleur à contribuer à l'armement d'un bâtiment traité par Vincent Postel et Pierre Le Cordier et destiné à « s'opposer aux invasions des pirattes écumeurs de mer et ennemis de l'Estat [...] le vaisseau sera propre pour attaquer et deffendre en quelque part que ce soit.".

119. BnF, Mél. Colb., ms 147, fol. 394-396 : lettre du duc de Saint-Aignan à Colbert du $1^{\text {er }}$ mars 1668 .

120. LE BER, Joseph, «Un organisateur de convois au XVII ${ }^{\mathrm{e}}$ siècle. Jacques Regnault de Rouen et Dieppe ", La Vigie de Dieppe, $1^{\text {er }}$ décembre 1939 : Regnault commande déjà en 1629 un bâtiment de 40 tx et 8 canons pour défendre les côtes du Ponant et les convois de sels de gabelles pour Le Havre.

121. Arch. dép. de Seine-Maritime, 2E1/2396, acte du 10 septembre 1651 : Regnault commet Guillaume Levasseur de Dieppe pour traiter d'octobre à Noël la garde et conservation des pêcheurs de harengs le long des côtes picardes et normandes avec les armateurs de Dieppe, Saint-Valéry-en-Caux, Fécamp par un vaisseau de 20 canons au Havre, et deux autres de 10 canons l'un et de 80 tx et 6 canons le second, ce dernier étant affrété à Dieppe.

122. DANIEL, Charles, Voyage à la Nouvelle-France du capitaine Charles Daniel, de Dieppe, 1629 ..., FÉLIX, Julien (éd.), Rouen, Henry Boissel, 1881, app. I, p. 41-45: faire-part d'inhumation de Jacques Regnault, 1691. LE BER, Joseph, « Un organisateur... », art. cité.

123. A NON, Almanach royal pour l'année 1714, Paris, Laurent d'Houry, 1714, p. 176 : François et Fabien Hazon frères, rue Saint-Martin près la rue aux Ours, marchands de vins et eau-de-vie, banquiers pour les remises de place en place. Les Hazon s'établirent comme marchands à Châteaudun au début du Xve siècle puis à Orléans en 1576 et à Paris vers 1650, échevins de Paris de 1710 à 1712. Famille alliée aux Colas des Francs d'Orléans, Coquebert de Montbret, Brongniart et les banquiers Lecouteulx de Paris. 
124. BnF, ms fr. 18592, fol. 398 ; LE BER, Joseph, «Un organisateur... ", art. cité et POPE, Peter E., Fish..., op. cit., p. 85 : William Barkeley, l'associé des frères Kirke, entre dans la commission des marchandises de prises de Londres en 1649. Pouliot, Léon, «Que penser des Frères Kirke?», Bulletin des Recherches Historiques, t. 44, 1938, p. 321-335: Gervaise Kirke, né dans le Derbyshire, a vécu une quarantaine d'années comme marchand anglais à Dieppe où il épouse Élisabeth Goudon et où naissent leurs enfants.

125. BоснасA, Michel, «La pluralité des activités, une forme de réactivité commerciale. L'exemple de Thomas de Bondié, bourgeois et marchand de Bordeaux (1505-1506)», Annales de Bretagne et des Pays de l'Ouest, 120-2, 2013, p. 79-96.

126. Arch. dép. de Seine-Maritime, 2E1/1173, acte du 5 janvier 1645 : assurance à Londres pour 150 livres de son quart d'intérêt sur le terre-neuvier Don de Dieu d'Honfleur et ibid., 201 BP 349, acte du 19 juin 1655 : perte de son terre-neuvier l'Unique César en 1655 avec 200 milliers de morues à bord.

127. Arch. dép. de Seine-Maritime, 2E1/2395, acte du 7 juin 1651 : ce heu construit « façon d'Angleterre » avait été pris par Roussel qui l'a conduit en relâche à Dieppe puis pour Ostende. Regnault devait faire charger des marchandises à Rotterdam pour Rouen après son acquisition.

128. Arch. dép. de Seine-Maritime, 2E1/2394, acte du 4 avril $1651 ; 2 \mathrm{E} 1 / 2396$, actes des 12 octobre et 15 décembre 1651. Regnault envoie à Amsterdam les marchands Jean Rasse puis Guillaume Levasseur pour régler les problèmes de réparations, fournitures et avitaillement du navire et de l'équipage.

129. Arch. dép. de Seine-Maritime, $2 \mathrm{E} 1 / 2392$, acte du 21 juin 1650 . Arch. dép. de SeineMaritime, 2E1/2490, acte du 27 mars 1660 : Regnault succède brièvement au marchand havrais Jean Deneufville dans la ferme du marquisat de Graville dépendant du prince de Condé pour un bail de 6 ou 9 ans pour le prix de 10500 livres par an.

130. Arch. dép. de Seine-Maritime, 2E1/2391, acte du 16 avril 1650 à 2E1/2396, acte du 24 novembre 1651 ; contrat renouvelé à chaque trimestre par avances successives de 900 livres.

131. Arch. dép. de Seine-Maritime, 2E1/2397, actes du 3 février 1652, du 24 avril 1652 et du 3 août 1652 stipulant que Mahier recrute, solde, nourrit et entretient les 21 hommes d'équipage, tant officiers que matelots, dont le rôle est déposé au greffe de l'amirauté du Havre, nourrit le commis des gabelles embarqué à bord durant la campagne de mer qui débute le 10 février 1652. Regnault fera l'avance des 6000 livres au capitaine reçues le 17 février de feu François Guymont. Le contrat initial est passé le 29 janvier 1652 devant Lecat et Richer, notaires au Châtelet de Paris, entre Regnault et les fermiers Pierre Mérault et Bonnaventure Quentin, associé fondateur de la $C^{\text {ie }}$ de la NouvelleFrance ; Arch. dép. de Seine-Maritime, 2E1/2399, acte du 27 avril 1652 : Regnault reçoit de 0 . de Gomont commis général des gabelles en Normandie 8100 livres pour couvrir l'armement et la campagne de la frégate. DESSERT, Daniel, L'Argent du sel. Le sel de l'argent, Paris, Fayard, 2012, p. 161: Oudart de Gomont est l'intendant du prince Maurice de Savoie et l'époux d'Olympe Mancini. Il participe à la recette des impôts de Guyenne et à la ferme du Convoi et comptablie de Bordeaux.

132. Arch. dép. de Seine-Maritime, 2E1/2525, acte du 11 février 1656 : le contrat porte sur 3 mois à compter du $1^{\mathrm{er}}$ mars suivant, à raison de 7200 livres par mois pour l'armement remis par Chanlatte, receveur de l'écu par tonneau de mer pour l'entretien des navires gardes-côtes. Signatures du duc de Longueville et du financier Claude 
Girardin. Cet acte est le dernier contrat d'affrètement connu de Regnault avec la ferme des gabelles; Arch. dép. de Seine-Maritime, 216 BP 371, ordonnance du 24 avril 1657, autorisant l'appareillage des navires neutres hollandais qui transportent et déchargent les sels des greniers du roi dans les ports de France pour le service de la gabelle.

133. KIRK, Thomas A., Genoa and the Sea. Policy and Power in an Early Modern Maritime Republic, 1559-1684, Baltimore, John Hopkins University Press, 2013, p. 145-146 ; CHET, Guy, The Ocean is a Wilderness. Atlantic Piracy and the Limits of State Authority, 1688-1856, Amherst-Boston, University of Massachusetts Press, 2014, p.55-56: résument l'ensemble des inconvénients liés aux convois marchands.

134. LE BER, Joseph, « Un organisateur... », art. cité.

135. Arch. dép. de Seine-Maritime, 204 BP 5, dossier Canivet : le tarif d'escorte payable huit jours après l'arrivée des bâtiments au quai de Rouen est de 70 sols par tonneau de cidre ou «perey» (poiré) en futaille non jaugée, 3 sols par pot de beurre et $2 \%$ ad valorem sur les autres marchandises, 15 décembre 1651.

136. Arch. dép. de Seine-Maritime, 216 BP 371, contrat du 8 juin 1655. Les Six Corps désignent les corps de métiers des marchands de Paris (drapiers, épiciers, merciers, fourreurs, bonnetiers et orfèvres). SURUN, Michel, Marchands de vin en gros à Paris au $17^{e}$ siècle. Recherches d'histoire institutionnelle et sociale, Paris, L'Harmattan, 2007 ; MARRAUD, Mathieu, De la Ville à l'État. La bourgeoisie parisienne XVII -XVIII siècle, Paris, Albin Michel, 2009, p. 116 : sur les marchands Planson, Raguenet et Mésaiger. Arch. dép. de SeineMaritime, 216 BP 371 : tarif de convoyage des marchandises depuis Isigny ou depuis Port-en-Bessin et ibid., 2E1/2411, acte du 15 juillet 1652 : tarif des trois vaisseaux d'escorte. ABAD, Reynald, Le Grand Marché..., op.cit., p. 698-702: sur le ravitaillement parisien en beurres normands.

137. Arch. dép. de Seine-Maritime, 216 BP 28 bis, p. 13 et 19 : Jean Mayer liquide par dicton devant l'amirauté du Havre un contentieux gagné en décembre 1657 contre le marchand havrais Charles Gomont. Mayer commande le terre-neuvier havrais l'Aurore mais doit rendre à son retour les comptes de sa campagne de pêche aux intéressés bourgeois du navire (Nicolas Ansel, Nicolas Gougeas, Nicolas Desmares le jeune, Pierre Adam, Estienne Legrin, Bonnaventure Chareau et Sulpice Morchoisne) le 23 novembre 1658.

138. MathoReZ, Jules, "Notes sur les Espagnols et les Portugais à Nantes", Bulletin Hispanique, t.14-15, 1912-1913, p.1-98: il écrit à propos des armateurs nantais: "[durant la guerre franco-espagnole de 1635-1659] on demeure surpris que les armateurs aient eu l'audace de continuer l'exercice d'un commerce qui offrait tant de périls et de dangers" ".

139. BRENNER, Robert, Merchants and Revolution. Commercial Change, Political Conflict, and London's Overseas Traders, 1550-1653, London-New York, Verso, 2003, p. 577-632. Arch. mun. du Havre, $49 \mathrm{Z}$ : les rares marchands haut-normands engagés dans le commerce antillais se replient vers d'autres trafics ou font faillite comme Isaac Boivin vers 1650.

140. PRESTWICH, Menna, "Diplomacy and trade in the Protectorate", The Journal of Modern History, vol. 21, 1950, p. 103-121. DE KREY, Gary S., London and the Restoration, 1659-1683, Cambridge, Cambridge University Press, 2005, p. 3-18; Ashley, Maurice, Financial..., op. cit., p. 174-178.

141. Jones, James R., The Anglo-Dutch Wars..., op. cit., p. 143. PRIESTLEY, Margaret, « AngloFrench trade and the "Unfavourable balance" controversy, 1660-85», The Economic 
History Review, $2^{\text {nd }}$ series, vol. 4, issue 1, août 1951, p. 37-52. LougH, John, France..., op. cit., p. 173.

142. Hirschman, Albert O., Les Passions et les intérêts. Justifications politiques du capitalisme avant son apogée, Paris, PUF, 2011, 4e éd., p. 37-38. LAVAL, Christian, L'Homme Économique. Essai sur les racines du néolibéralisme, Paris, Gallimard, 2007, p.56-57. GUERY, Alain, «L'honneur et le profit. Économie du pouvoir et économie de la richesse chez Montchrestien » dans GUERY, Alain (dir.), Montchrestien et Cantillon. Le commerce et l'émergence d'une pensée économique, Lyon, ENs Éditions, 2011, p. 417-439. POLANYI, Karl, La Grande Transformation, Paris, Gallimard, 1983, p. 91 et 112-116, écrit que « La découverte la plus marquante de la recherche historique et anthropologique récente est que les relations sociales de l'homme englobent, en règle générale, son économie. L'homme agit de manière, non pas à protéger son intérêt individuel à posséder des biens matériels, mais de manière à garantir sa position sociale, ses droits sociaux, ses avantages sociaux ».

143. Arch. dép. de Seine-Maritime, 204 BP 5, dossier Canivet, sieur du Taillis, 1651.

\section{RÉSUMÉS}

Les statistiques portuaires du Havre montrent que la violence maritime généralisée en Manche comme en mer du Nord, les tensions politiques et sociales ainsi que la corruption administrative perturbent considérablement les activités commerciales des marchands-armateurs normands durant la décennie 1650. Les milieux marchands normands s'adaptent en pratiquant la résilience marchande contre la piraterie ou la guerre de course; certains d'entre eux s'engagent dans la pluriactivité commerciale, organisant par exemple des convois d'escorte pour les caboteurs le long des côtes de Normandie.

The statistics of Le Havre harbour in the 1650s emphasise how much violence, administrative corruption, and socio-political tensions in the Channel and the North Sea considerably disturbed the commercial activities of merchant ship-owners in Normandy. Commercial groups adapted their strategy to meet the threat of piracy and privateers, others diversified their activity by, for example, organising convoys along the Normandy coasts.

\section{INDEX}

Thèmes : Normandie

Index chronologique : XVIIe siècle 
AUTEUR

ÉDOUARD DELOBETTE

Chercheur associé au CRHQ/MRSH, université de Caen-Normandie 